\title{
The Effect of Single Sessions of Music Therapy on the Level of Anxiety in Older Persons With Psychiatric Disorders - A Pilot Study
}

A thesis presented in partial fulfilment of the requirements for the degree of

\author{
Master \\ of \\ Music Therapy
}

at the New Zealand School of Music, Wellington, New Zealand.

Word Count: 20,300

Ajay Castelino

2009 


\begin{abstract}
This pilot study examined the effects of single sessions of music therapy on the level of anxiety in older persons with psychiatric disorders. The studied intervention was a 30 minute music therapy group and the control intervention was a verbal therapeutic intervention in the form of a reminiscence group. Participants acted as their own control. The measurement tool was the state part of a "State Trait Anxiety Inventory". It was administered a total of four times, pre- and post- the music therapy intervention and preand post- the reminiscence therapy (control) group. A total of 9 participants were recruited for the study. The results indicated that single sessions of music therapy significantly reduced the level of anxiety for older persons with psychiatric disorders $[\mathrm{t}(8)=4.626, \mathrm{p}<0.0017]$ as compared to the control intervention as measured by the state part of the "State Trait Anxiety Inventory". There was no evidence for a significant carryover effect since the baselines prior to each intervention did not differ significantly $(\mathrm{p}=0.55)$. These results can be considered to be a part of a pilot study and early inquiry into this field since methodological difficulties and the time limitation of the research resulted in some necessary deviations from the original protocol. A major limitation of the study was the choice of a measurement tool, which required the client to be cognitively high functioning. Thus these results are limited to cognitively able clients, which is a relatively small proportion of this client group that could potentially benefit from music therapy. It is suggested that for future research with this client group the measured variable be physical relaxation, rather than anxiety.
\end{abstract}




\section{Acknowledgements}

The author thanks and acknowledges the assistance of

Associate Professor Sarah Hoskyns, Supervisor

Director of Music Therapy,

New Zealand School of Music

Mental Health Services for Older Persons Team -

Sarah Harrison, Occupational Therapist \& Clinical Liaison

Shelley Seed, Senior Occupational Therapist

Alison Robertson, Research Officer

Greg Gamble, Biostatistician

\section{Special thanks to}

Lorraine and my family for all their emotional support

The project has the approval of the Northern X Regional Ethics Committee, New Zealand (NTX/08/08/055) 


\section{Table of Contents}

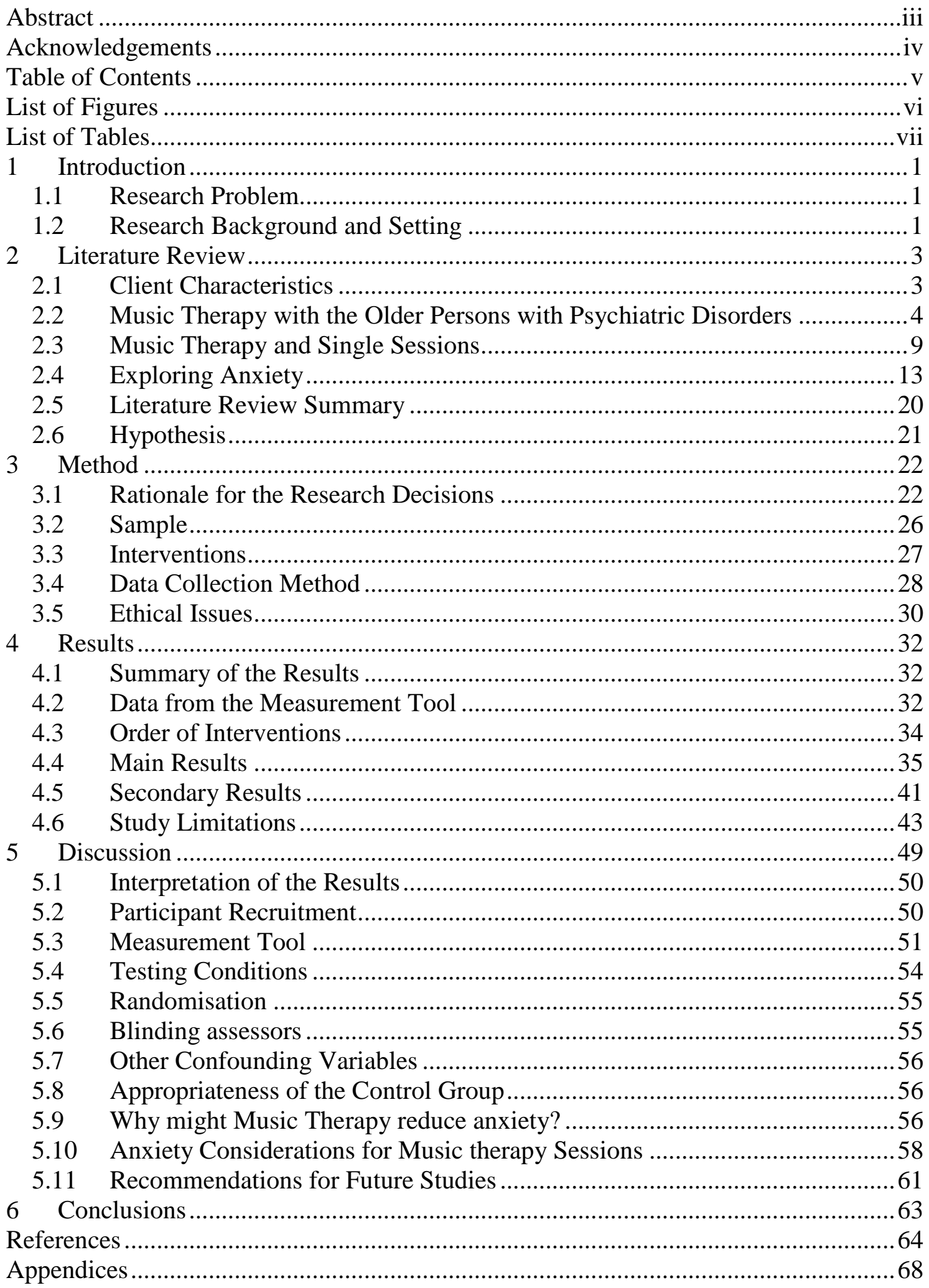




\section{List of Figures}

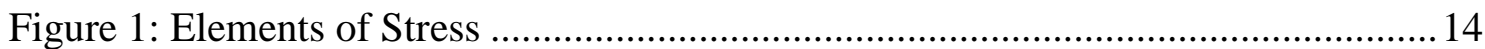

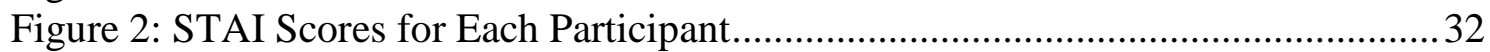

Figure 3: Difference (control-music) in Change (pre-post) in State Domain ...................38

Figure 4: Difference In Scores Between Pre-Music Therapy And Pre-Control For Each

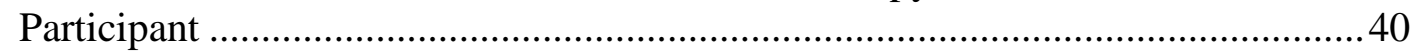

Figure 5: Change In Scores For Each Participant For Both Interventions...................... 43

Figure 6: Difference In Changes In Scores Between Pre-Control And Pre-Music

Therapy With the Exclusion of One Score for the Participant Measured Twice....46

Figure 7: Comparing the Hospital to Rest Home Settings...........................................48

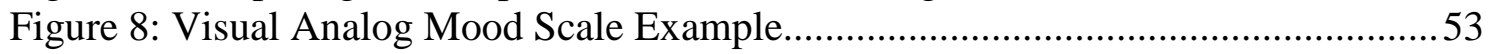




\section{List of Tables}

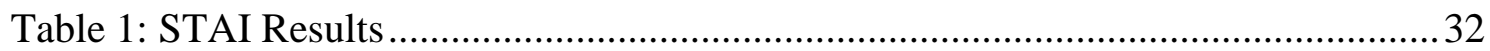

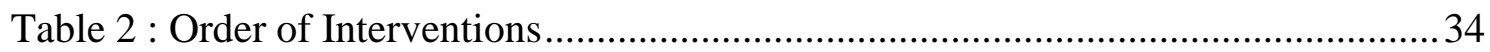

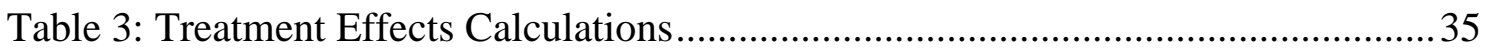

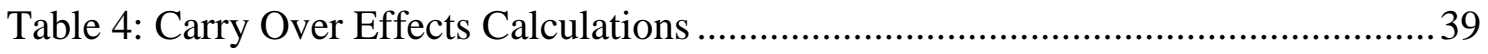

Table 5: Comparison Of Pre-Intervention Scores For Each Participant ........................ 41

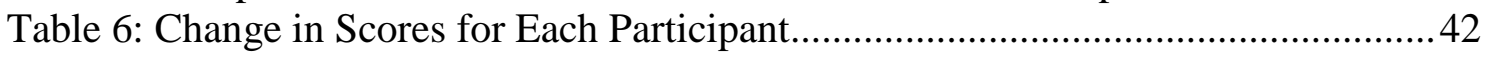

Table 7: Deviations From the Proposed Research Design........................................... 43

Table 8: Treatment Effect Calculations without One Score for the Client Measured

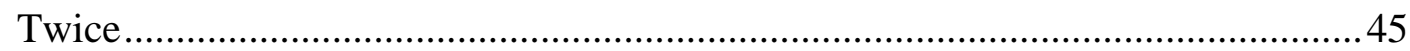

Table 9: Comparing Interventions In Different Settings.......................................... 47

Table 10: Comparative Analysis of the Rest Home (Individual) And Hospital (Group)

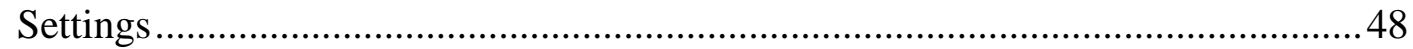

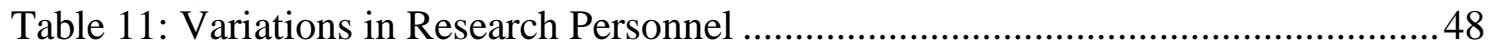

Table 12: Anxiety Measurement Scales for Older Persons .........................................52 


\section{Introduction}

\subsection{Research Problem}

This research was designed to investigate the effect of single sessions of music therapy on anxiety in older persons with psychiatric disorders in an acute admission service. The literature search carried out for this study identified no current research that contained all the research study variables of a single session, music therapy, anxiety and older persons with psychiatric disorders. Most music therapy research literature with this client group focused on longer term music therapy interventions. The reality of the process for most acute admissions in psychiatry is that clients may only be able to attend a single session of music therapy because the average stay in an acute setting is between one to three weeks. Therefore a research project that explored the change in anxiety before and after single sessions of music therapy with this client group was considered beneficial to evaluate the effects of music therapy within this area.

\subsection{Research Background and Setting ${ }^{1}$}

This research project arose from a music therapy student placement, which formed a part of the New Zealand School of Music - Master of Music Therapy programme. The placement was for one and a half days a week from March to November 2008. This research was conducted with the team from "Mental Health Services for Older People" at a large general hospital in New Zealand. The team provided an integrated assessment and treatment service for older adults (65 and over) with mental health problems or dementia with bi-polar syndrome disorder (BPSD), and younger adults with early onset of dementia and BPSD. This service consisted of a 15 bed capacity inpatient acute unit and a multidisciplinary community mental health team.

The criterion for a person to be referred for an assessment and admission to the inpatient acute unit was a diagnosis of a mental health disorder that required specific medical, nursing or other paramedical treatment. It included those individuals who by virtue of their mental state represented a substantial risk to themselves or others and who were

\footnotetext{
${ }^{1}$ The information in this section "Research Background and Setting" was obtained from the "Operational Manual" for the department at which the research was carried out. For confidentiality purposes this document has not been referenced. If further information about this section is required, please contact the researcher or research supervisor.
} 
detained under the terms and conditions of the Mental Health Act. Patients were also referred if they suffered from a profound mental illness that resulted in behaviours or levels of dependence that could not be safely managed in other environments and which required nursing or medical intervention.

The community team offered a multidisciplinary service to older persons in the community who required specialised mental health assessment and management. The services provided included home visits, specialised assessment, treatment, ongoing follow up, liaison with other services, advice and support for carers and families, inpatient admission if required, education and advocacy in the area of mental health services for older people.

Music therapy sessions were carried out at the ward and also within the community. In the ward, group sessions were run every week. All the patients whom the staff considered appropriate were invited to participate. Usually there were between 3 to 6 participants attending each session. The sessions occurred in the meeting room within the ward. They consisted of live music, including pre-composed songs and instrumental improvised music. A number of instruments were also made available for the clients to explore and use in music making. The music used during the sessions was client centred and adapted to meet the social, emotional and cultural needs of the given group.

Other work was done in the community at rest homes and residences of patients who were under the community team. These patients presented with psychiatric symptoms, though were not in an acute state and therefore did not need to be admitted to the hospital. Patients whom the community team felt would benefit from music therapy were referred for an initial music therapy assessment. The aim of the assessment was to determine if music therapy was appropriate for the client. If deemed appropriate, individual sessions were scheduled for them with a focus on using music to help achieve the care plan goals for the patient. 


\section{Literature Review}

\subsection{Client Characteristics}

In New Zealand the proportion of people aged 65 and over in 2006 was $12.3 \%$ and this is predicted to rise to over $25 \%$ of the population by 2051 (StatisticsNZ, 2007). The key document that frames the health of this increasing population of older persons in New Zealand is the "Health of Older People Strategy" (Ministry Of Health MOH, 2002). It outlines the targets and aims for meeting the health requirements for this client group. This document identifies mental health as being an important issue for older persons. It indicates that, "Older people with a physical illness or disability have a greater tendency than others to have or develop psychiatric symptoms such as depression or treatmentrelated psychoses" (MOH, 2002 p.30).

The main psychiatric conditions attributed to this client group are: dementia, delirium, depressive disorders, manic syndromes, neurotic disorders, late-onset schizophrenia, very-late onset schizophrenia-like psychosis and substance abuse (Jacoby \& Oppenheimer, 2002). The standard symptoms of psychiatric illness are differently manifested for this client group due to effects of old-age complicating the resulting presentation by the clients. These effects include overall diminished ability in all functions; general decline of good health and having to adjust to changes within the environment such as retirement, loss of close relatives and friends, moving house and loss of social roles (Raijmaekers, 1993).

The treatment of these conditions is usually carried out by a team that utilises pharmacological and psychological interventions. For example, the "Mental Health Services for Older People" team within which the current research was carried out consisted of a varied range of professionals such as psychiatrists, nurses, psychologists, social workers and occupational therapists. Music therapy can be considered to be a psychological intervention. There are four main branches of psychology of particular value with older people (Jacoby \& Oppenheimer, 2002). These are listed below. 
1. Clinical approach: Psychological models are used to understand, reduce emotional distress (eg: depression, anxiety, anger and shame) and address behaviours experienced as unhelpful by the patients, families or staff.

2. Health approach: Psychological models are used to understand and, if appropriate, adapt unhelpful health-related behaviours (for example: noncompliance with medication) and responses to physical illness.

3. Cognitive approach: Investigation of the thinking processes, the impacts of thoughts upon emotions and behaviour, and vice-versa.

4. Neuropsychology: Identification and measurement of perceptual abilities and cognitive functions such as memory, language, information processing and planning.

These psychological interventions are provided by a number of different professions. Perkins (2004) provides a comprehensive list of the psychological interventions used in the treatment of dementia in New Zealand. Although these interventions are listed specifically for dementia clients, they provide a good basis of information for therapeutic interventions with older persons with psychiatric disorders. This list includes occupational therapy, dietetics, psychology, physiotherapy, social workers, speech therapy, music therapy, behaviour modification therapy, cognitive behavioural therapy, validation therapy, reality orientation, reminiscence therapy, acupuncture, aromatherapy, herbal remedies, homeopathy, Maori traditional healing, reflexology, art therapy, massage and doll therapy.

\subsection{Music Therapy with the Older Persons with Psychiatric Disorders}

This literature search identified a body of literature in relation to older persons in general. Internationally, authors such as Bright (1991), Aldridge (2000) and OdellMiller (2005) have published research in this field. In New Zealand as well, articles have been published that explore the use of music with older persons (Brooks \& ORourke, 1992; Hepburn, 1997; Rickson, 1998; Webster, 1994). However, when focussing on elderly mentally ill, it was found that most of the research specifically related to clients with dementia. 
In New Zealand, overall 1 in 40 adults have been diagnosed with a serious mental illness (depressive disorder, bipolar disorder or schizophrenia) (MOH, 2004). There is minimal music therapy research internationally specifically relating to psychiatric symptoms such as schizophrenia in older persons. Early indications of the lack of research in this field were identified by Odell-Miller (1995). Odell-Miller (1995) also indicated that the research prior to 1995 tended to focus on music teaching rather than music therapy strategies. This has continued to the present day. The available literature for this client group and relevant generalised literature for mental health disorders are summarised below.

\subsubsection{Diagnosis and Assessment}

Raijmaekers (1993) writes about the role of music therapy as part of the diagnostic team for a psycho-geriatric unit. The author explains that clients with a functional psychiatric disorder may have their cognitive functions disturbed however their internal emotional state may still be intact. Cognitive dysfunction is said to be related to the cortical region of the brain while emotions are said to use the limbic system as an important neurological circuit. Music enters through the ears and brainstem and it may influence the limbic system directly, even before entering the cortex. Therefore, music may enable understanding of the emotional state of a cognitively impaired client. Raijmeakers (1993) argues that a music therapy assessment with this client group could provide unique information for the assessment team. Raijmeakers's (1993) music therapy assessments focussed on the fields of emotion, cognition and communication. Raijmeakers (1993) detailed that the information gained included areas such as the ability to understand instructions, free associate, choose, explore and combine ideas; long and short term memory; musical language, ability, contact and interaction; reactions to simple and complex situations and social functioning.

\subsubsection{Dementia}

Dementia is a clinical syndrome characterised by the development of multiple cognitive deficits (including memory impairment) that are due to the direct physiological effects of a general medical condition, to the persisting effects of a substance or to multiple etiologies (e.g.: the combined effects of cerebrovascular disease and Alzheimer's disease) (DSMIV, 1995). The common types of dementia are Alzheimer's disease, vascular dementia, mixed Alzheimer's disease and vascular dementia, lewy body 
dementia and frontotemporal dementia (Perkins, 2004). As indicated above, the majority of the music therapy studies with older persons with psychiatric disorders focus on dementia patients. The following studies summarise the research carried out in this field.

Sherratt, Thornton and Hatton (2004) carried out a review of 21 published articles of clinical empirical studies on the effects of a variety of music activities on the emotional and behavioural responses in people with dementia. The results indicated that most of the studies reported music to be effective in decreasing a range of challenging behaviours including aggression, agitation, wandering, repetitive vocalizations and irritability. Music was also found to increase reality orientation scores, memory recall, time spent with one's meal, engagement, participation and improved social behaviour. This review provides a comprehensive list of the areas where music is used with dementia clients.

An investigation of the effectiveness of these interventions was carried out in a study by Vink, Birks, Bruinsma and Scholten (2003). They carried out a Cochrane review to assess the effects of music therapy in the treatment of behavioural, social, cognitive and emotional problems for older people with dementia. Cochrane Reviews investigate the effects of interventions for prevention, treatment and rehabilitation in a healthcare setting (Cochrane, 2009). They are designed to facilitate the choices that doctors, patients, policy makers and others face in health care. Most Cochrane Reviews are based on randomized controlled trials, but other types of evidence are also be taken into account, if appropriate. Vink et al. (2003) concluded that the methodological quality of the studies reviewed was generally poor and therefore the study results could not be validated or pooled for further analysis. They indicated that more rigorous studies were needed to establish whether music therapy might play a role in the treatment of older people with dementia. They suggested that future trials should include conditions such as randomisation, concealing the allocation of participants to treatment groups, blinding the outcome assessors to treatment allocation, including reliable and validated outcome measures, be of sufficient duration to assess medium and long-term effects and follow the Consolidated Standards of Reporting Trials (CONSORT) guidelines. The CONSORT guidelines provide an evidence based, minimum set of recommendations 
for the reporting of Randomised Control Trials (RCT's) (CONSORT, 2009). It was designed to alleviate problems arising from inadequate reporting of RCT's.

Based upon these recommendations, Bruer, Spitzriagel and Cloninger (2007) designed a study to explore the temporal limits of cognitive change from music therapy in elderly persons with dementia or dementia-like cognitive impairment. The study was an 8 week randomised control trial using a cross-over design. The assessors were blinded to the subjects' assigned intervention. The assessment tool used to assess cognition was the "Mini Mental State Examination." The results showed a significant difference between the baseline (pre-session) and the morning-after results. However the results for the comparison between the baseline (pre-session) and immediately after the session (postsession) were not significant. The conclusion was that a music therapy intervention facilitated by a trained and accredited music therapist significantly improved nextmorning cognitive functioning among dementia patients.

\subsubsection{Schizophrenia and Psychosis}

Schizophrenia is a disturbance that lasts for at least six months and includes at least one month of two or more active-phase symptoms which are delusions, hallucinations, disorganised speech, grossly disorganised or catatonic behaviour and negative symptoms (DSMIV, 1995). No research was found that specifically related to the use of music therapy with older persons with schizophrenia or psychosis. However, the articles that assessed the effectiveness of music therapy for clients with this diagnosis are summarised below.

The majority of articles on music therapy with clients with schizophrenia and psychosis have been qualitative. Silverman (2003) indicated that they provide information that may not be generalised to other clients with the same diagnosis or objectives. Therefore, Silverman (2003) carried out a meta-analysis to summarise the quantitative research literature that evaluated the influence of music upon the symptoms of psychosis. The results provide a summary of the use of music therapy with this client base. The results showed that music therapy was statistically significant in suppressing and combating the symptoms of psychosis. However there were no differing effects between live versus recorded music, structured music therapy groups versus passive listening, preferred 
versus therapist-selected music. The research also indicated that classical music did not prove as effective as non-classical music.

A further analysis was carried out done by Gold, Heldal, Dahle and Wigram (2005). They carried out a Cochrane review into the effects of music therapy for people with serious mental illnesses such as schizophrenia. The conclusion was that if a sufficient number of sessions were provided, music therapy as an addition to standard care helped people with schizophrenia to improve their global state and may also improve their mental state and functioning. They suggested that further research could address the dose effect relationship and the long-term effects of music therapy.

\subsubsection{Depression}

Hanser \& Thompson (1994) investigated whether music facilitated psycho-educational strategies for depressed older adults experiencing symptoms of depression, distress and anxiety could be administered within a home setting. The idea of the intervention was to provide access to psychotherapeutic interventions to older adults who were homebound and could neither afford nor travel away from home. The study involved the participants engaging in music listening strategies that were either supported by weekly home visits or weekly telephone calls by the music therapist. The control group was the wait list. The results indicated that participants in both music conditions performed significantly better than the controls on standardised tests for depression, distress, self-esteem and mood. In addition these improvements were maintained over a 9-month follow-up period.

Suzuki (1998) examined the effects of music therapy on mood changes and accessibility of positive and negative memories among depressed elderly individuals in a residential rest home. The participants received 9 music therapy sessions over 3 weeks. The results indicated that the negative moods of the participants significantly decreased after participating in music therapy sessions and the subjects recalled unpleasant past events significantly less frequently after music therapy. These findings are said to imply that music therapy may assist depressed elderly individuals who reside in residential care homes in decreasing negative moods and negative memories. 


\subsubsection{General Studies}

Odell-Miller (1995) carried out research into the use of music therapy with elderly mentally ill. The research consisted of two parts. Part one consisted of eight music therapy and reminiscence therapy (control) sessions. The hypothesis was that the clients would show a greater level of engagement during music therapy than during the control group. The results indicated no significant difference between the levels of engagement in the two conditions. In part two of the research, 12 weekly music therapy sessions were carried out to measure the cumulative effect of weekly music therapy. In addition to pre- and post- the session, measurements were also taken 30 minutes after the session on music therapy and non-music therapy days to measure the longer-lasting effects of music therapy. The hypotheses were that there would be a greater level of engagement during the last few sessions compared to the first three sessions and also a higher level of engagement, 30 minutes after music therapy than on a non-music therapy day. The results showed that there was increasing engagement as the sessions progressed. There also was increased engagement during the music therapy sessions than 30 minutes after the sessions. However, there was no evidence that engagement was greater in the period after music therapy sessions than on the days when no music therapy was provided.

In summary, the literature on music therapy with older persons with psychiatric disorders indicates that music therapy has positive benefits for this client group. The reviewed authors indicate that the music therapy quantitative research in this field carried out in the future would need improved methodological standards.

\subsection{Music Therapy and Single Sessions}

\subsubsection{The Practicalities of Research in Psychiatry}

Silverman and Marcionetti (2004) noted that research concerning persons who were severely mentally ill was intricate and difficult to control. They explain that research in psychopathology has many complications such as the presence of obscure and unreliable data, choosing between scientifically safe and clinically significant problems, issues of clinical responsibility and ethics and complications of execution. Aldridge (as cited in M. J. Silverman \& Marcionetti, 2004) is also said to note the difficulties in quantitative research in the psychiatric field. These difficulties consist of finding matching groups of acute psychotic patients using the parameters of age, syndrome, and 
diagnosis that are not complicated by other problems such as alcohol or drug dependency; medication variables and different crises and issues for psychotic breakdown. These are all said to contribute to relatively small numbers of participants. To minimise the effects of these variables on the research, Silverman and Marcionetti (2004) proposed a single session intervention with a pre- and post- test design with subjects as their own control. They mentioned that the single session intervention with a pre- and post-test design ensures that the controls are maximised and the results are minimally influenced by other variables. These practical issues raised by Silverman and Marcionetti (2004) were also present within the current medical ward where this research was carried out. Music therapy is traditionally a long-term intervention with the gradual development of a therapeutic relationship with the client. Research (by music therapists in a variety of fields) on single music therapy interventions, its challenges and methods of working are summarised below.

\subsubsection{Single Sessions and Psychiatry}

Silverman and Marcionetti (2004), evaluated the immediate changes in common psychiatric deficit areas in patients with severe mental illnesses during a single music therapy intervention. The psychiatric deficit areas were identified as self-esteem, selfexpression, coping skills, anger management, mood, symptoms, how the participants felt about their situation at hospital and how the participants felt about music therapy. The effects of 5 different music therapy interventions were compared for each specific psychiatric deficit areas. The five music therapy interventions were facilitated group drumming, music games, lyric analysis, song-writing, and music listening. The results demonstrated that irrespective of the intervention or therapeutic technique used, music therapy consistently was rated as positively influencing participants. Future research suggestions included comparing music therapy to a control group to strengthen the research design. The other suggestion was that observational data tracked by a mental health professional might provide more objective results than self-report data. The use of a reliable testing instrument was another recommendation. It was suggested that the concept of using the clients, as their own control should be continued since each participant had unique symptoms, issues and medication variables.

The study by Bruer et al. (2007) listed in section 2.2.2 also has an element of a single session intervention. It identifies that pre- and post- session measurements of single sessions appear to be useful for demonstrating cognitive change within participants. 


\subsubsection{Psychotherapeutic Considerations for Single Sessions}

The practice of music therapy occurs within various frameworks such as humanistic, behavioural, psychodynamic and Guided Imagery and Music (GIM) (Wigram et al., 2004). Practioners of a psychodynamic approach to music therapy have written articles about the considerations and adaptations of utilising this approach for short-term work. Psychotherapeutic music therapy interventions are traditionally long term where the therapeutic process can gradually unfold. Ideas such as containment, boundaries and holding can be developed. Trust can also be gradually built upon and therapeutic themes can begin to emerge (Molyneux, 2005). However for single sessions, boundaries such as meeting at the same place and time for every session are absent. A few music therapists have written about structures that have to be put into place to accommodate these concepts in short term work.

Molyneux (2005) writes about short-term music therapy work with individuals and families in a child and adolescent mental health service. Within this article, the author offers ideas regarding containment and boundaries. The author states that the key features of short term interventions need to be a clear statement of aims, protection of the therapeutic space for the client, a focus on the therapeutic aims during the session, clarity concerning endings and an open process for evaluating and reviewing progress that involves the client and their carers. These processes are said to offer a safe and fruitful therapeutic space for the clients and the therapist.

Rickson (2006) believes that the psychotherapeutic concept of the "holding" function can be achieved through musical improvisation for single session interventions. The author explains that even a single improvisation is said to be able to convey and receive many of the virtues intrinsic to the therapeutic relationship. Within this single improvisation the therapist is said to be able to meet the client in the moment, gain information about the client's level of functioning and support and encourage the client to participate at levels that he or she has perhaps not experienced before.

\subsubsection{Other single session interventions}

Krout (2005) discusses the benefits of one-time grief-related support groups and programs. The benefits of these one-time sessions are said to be that they allow the bereaving person to "check in" with how they are doing, get reassurance that they are 
grieving "normally" and "feeling or doing the right things." It is also said to allow staff members to assess if the bereaved person is adapting to life after the loss in a healthy way and to offer further grief services if such needs are identified. This article explores the use of therapist-composed songs to meet the single session goals. It is explained that due to the time limitations of single session interventions it is preferable for the therapist to pre-compose relevant songs rather than use techniques such as song parody or facilitation of client-composed songs. The benefit of using original songs rather than standard songs is said to be that the song lyrics and structure can better be composed to meet the specific needs of the individual and thus probably obtain a more efficient result. Krout (2005) achieved this goal via pre-identifying the members who would be attending the given group and pre-planning the song accordingly.

Ayson (2008) describes her research that explored the role of music therapy in supporting child-parent well being in a paediatric ward. The author explained that music therapy was offered at the facility for one day of the week and therefore in most cases patients were not admitted long enough to receive more than one session of music therapy. Therefore the sessions were designed to achieve meaningful outcomes in a single session. The study involved analysing clinical notes, semi-structured interviews with parents and a staff member and a personal reflective journal to study the effects of single sessions of music therapy on three children. The results showed that single sessions of music therapy for the children promoted normalisation and provided emotional/psychological support. For parents, it helped elicit positive changes in mood, reduce anxiety and support parental learning/parenting.

Krout (2001) carried out a study into the effects of single sessions of music therapy on the observed and self-reported levels of pain control, physical comfort and relaxation in hospice patients. The study concluded that music therapy interventions appeared to be effective in increasing the subject's pain control, physical comfort and relaxation during both observed and self-reported data collection scenarios.

\subsubsection{Single Sessions and Anxiety}

Most of the single session studies that were found in the literature considered anxiety as one of the main research variables. In clinical settings, research into the effects of music therapy on anxiety included studies with patients undergoing chemotherapy (Ferrer, 
2007); paediatric patients during donor site dressing changes (Whitehead-Pleaux et al., 2006); paediatric patients due to undergo surgery (Whipple, 2003); coronary care units (Bonny, 1983), ventilator-dependent patients (Chlan, 1998; Wong et al., 2001) and substance abuse patients (Cevasco, 2005). There also were a number of experimental single session studies that analysed the effects of music on anxiety (Knight \& Rickard, 2001; Robb, 2000; Walworth, 2003). The researchers indicated that anxiety presented as a common symptom for hospitalised patients. Single sessions of music therapy are identified as beneficial to reducing anxiety in these settings. The section below explores anxiety and the uses of music therapy to aid its reduction.

\subsection{Exploring Anxiety}

Anxiety disorders are classified as mental disorders as per the "Diagnostic and Statistical Manual of Mental Disorders" (DSMIV, 1995). These disorders include Panic Disorder Without Agrophobia, Panic Disorder with Agoraphobia, Agoraphobia Without History of Panic Disorder, Specific Phobia, Social Phobia, Obsessive-Compulsive Disorder, Posttraumatic Stress Disorder, Acute Stress Disorder, Generalised Anxiety Disorder, Anxiety disorder Due to a General Medical Condition, Substance-Induced Anxiety Disorder and Anxiety Disorder Not Otherwise Specified.

There are numerous definitions of anxiety that were identified throughout literature obtained for this study. However, having a standard definition and understanding of anxiety is an essential step to exploring means of anxiety reduction. The following understanding of the concept of anxiety presented as a common-sense explanation of this term and was congruent with other texts such as Goldberger and Breznitz (1982) and Wolpe (1982) studied about the same topic.

Anxiety can be identified as an element of a state of stress (Spielberger, 1979). Stress is a complex psychobiological process that consists of three major elements as listed below and represented in figure 1.

- A stressor, which is a situation, or stimulus that is potentially harmful or dangerous to an individual initiates this process.

- The next element is the perception of this stressor by the individual. The individual could perceive the stressor as dangerous or threatening..

- If this occurs then it elicits a state of anxiety in the individual. 


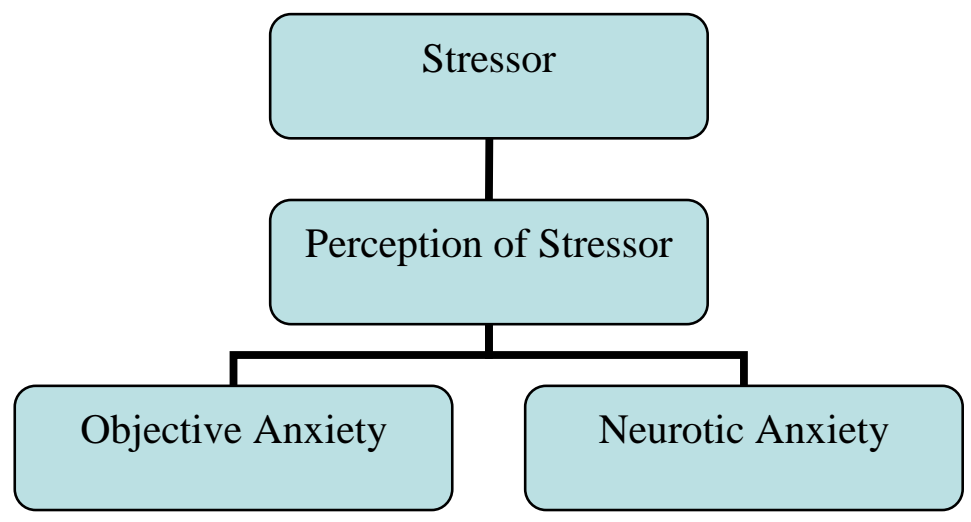

Figure 1: Elements of Stress

Anxiety can be classified into two types (Spielberger, 1979)

- Objective Anxiety: This is a reaction or response to a real danger in the external world. This is a normal adaptive reaction to external stimuli that serves to act as a danger signal that mobilises an individual for coping with harmful situations. Consequently, the reaction to this stressor is usually proportional to the perceived danger.

- Neurotic Anxiety: This is the reaction or response to thoughts and memories of repressed traumatic experiences. It is maladaptive and mobilises the individual to respond based upon repressed memories of dangers that no longer exist. Thus, there may be no real danger, only a perception of danger. Consequently, the reaction may not be in proportion to the perceived threat.

\subsubsection{Physiological Effects of Anxiety}

When an individual enters a state of anxiety, the body reacts with a fight-or-flight response (Spielberger, 1979). In this reaction, the body mobilises its resources to either attack an enemy or to escape to safety. Traditionally, this is an adaptive reaction that serves to mobilise a person for coping with harmful situations. However, the energy needed to prepare the body for the fight-or-flight response utilises energy needed for other bodily functions. Consequently regular arousal of a state of anxiety can cause physiological damage since there are limits to the adaptive capacity of an organism. 
Humans tend to exhibit stereotypical bodily reactions and experiences when in a state of anxiety (Spielberger, 1979). Low to moderate anxiety is characterised by feelings of apprehension, tension and nervousness. Moderate to high levels of anxiety are characterised by restlessness, trembling, shortness of breath, sweaty palms, increased heart rate, rise in blood pressure and muscular tension. High levels of anxiety are characterised by overwhelming fear and sometimes, panic behaviour.

\subsubsection{Techniques to reduce anxiety}

The following are the broad categories that are used to reduce anxiety (Spielberger, 1979).

- Psychotherapy, which gives the patient an insight into how repressed feelings, associated with childhood events contribute to their present anxiety issues.

- A behavioural therapy approach that aims to convince the client that neurotic anxiety is caused by their faulty perception or irrational fears about stressful events, rather than the event itself.

- Use of techniques such as meditation to relax the mind and body. A conscious effort to relax is said to be effective in relieving tension and anxiety.

- Use of chemical substances to diminish anxiety symptoms.

\subsubsection{Music Therapy and Anxiety}

The majority of literature in relation to music therapy and anxiety relates to its use in hospital settings. Walworth (2003) mentioned that the benefits of lower anxiety in clinical settings were decreased length of stay, decreased medication such as sedatives and pain relievers and an overall increased positive perception of the hospitalisation experience.

Music therapy is sometimes used before hospital procedures to reduce the anxiety of patients. Whipple (2003) provides anecdotal evidence of a music therapy program entitled "Surgery Buddies" that involves the paediatric patients and their families in music activities prior to surgery decreasing opportunities for anxiety to develop. The author explained that the program assisted not only the patient in coping with hospitalisation, but also the patient's family in managing their own anxiety and the hospital staff in carrying out the necessary surgical preparation procedures. 
Music therapy has also been used during hospital procedures to aid reduce patient anxiety. Ferrer (2007) demonstrated significant improvements on the measures of anxiety, fear, fatigue, relaxation, and diastolic blood pressure for clients who listened to familiar live music during chemotherapy as compared to those who had no music. Whitehead-Pleaux (2006) studied the effects of music therapy on pain and anxiety in paediatric burn patients. However, the results were mixed and inconclusive.

Chlan (1998) studied the effects of music therapy on relaxation and anxiety reduction for patients receiving ventilatory assistance. The conclusion was that a single music therapy session was found to be effective for decreasing anxiety and promoting relaxation, as indicated by decreases in heart rate and respiratory rate. Music listening as a type of music therapy intervention is also often carried out in clinical settings. Biley (2000) identified that music listening to reduce anxiety has been used in settings such as during anaesthesia, magnetic resonance imaging, dental settings and following coronary bypass surgery operations.

Music therapy can sometimes be carried out with other activities to aid anxiety reduction. Cevasco (2005) compared the effects of movement-to-music, rhythm activities, and competitive games on depression, stress, anxiety and anger in females in substance abuse rehabilitation. The results indicated no significant differences for the three types of music therapy interventions. However, pre- and post- session results indicated that individuals reported a decrease in depression, stress, anxiety, and anger immediately following the music therapy sessions. Robb (2000) carried out a study to compare the effects of music assisted progressive muscle relaxation, progressive muscle relaxation, music listening and silence on measures of anxiety and perceived relaxation. The results revealed that each treatment condition was equally effective in producing significant changes in anxiety and perceived relaxation from the pre- to the post- test period.

Some studies compare the effects of various music therapy techniques on reducing anxiety. For example, Jones (2005) compared song-writing and lyric analysis techniques to evoke emotional change in a single session with people who were chemically dependent. The results indicated that for both interventions, music therapy elicited significant emotional change during a single session and was perceived as 
therapeutic by the participants. The results also indicated a reduction in anxiety though the results were not statistically significant.

Only one study was found relating anxiety specifically to psychiatric clients. Choi, Lee and Lim (2008) carried out a study to test whether group music therapy was effective for improving depression, anxiety and relationships in psychiatric patients. The intervention was for 15 sessions and the control group was a routine care group. The results were that the music therapy intervention showed significant improvements in depression, anxiety and relationships compared with the control group.

\subsubsection{Type of Music and its Effect on Anxiety}

People often classify certain music as anxiety reducing or relaxing music. Music therapists have carried out studies to validate and identify the type of music that would result in anxiety reduction. Walworth (2003) states that usually music used to reduce anxiety and increase relaxation is slow in tempo and instrumental (that is, no lyrics). However, she explains that if a person has a history of negative association with a particular genre, then the person would not be able to relax with this music and might even become more tense than he or she would have without music. Based upon this premise, Walworth (2003) designed a study to examine the effects of listening to a song from the subjects preferred music genre, preferred song selection or listening to no music. The results indicated that there were no significant differences between the two music groups however subjects listening to music, showed statistically significantly less anxiety than subjects not listening to music.

Hanser (1988) also had identified familiarity and preference of the music selection as important factors to reduce anxiety via music listening. However she also identified slow tempi, lengthy phrases and soft dynamics as necessary ingredients. While giving directions for future research, Hanser (1988) stated that it was not clear whether the music must mirror the listener's mood by starting out at a faster tempo with a gradual change in dynamics and tempo.

\subsubsection{Measurement of Anxiety}

Anxiety is usually measured by observing subjective or physiological responses of individuals (Knight \& Rickard, 2001). Psychological (subjective) anxiety is measured 
via questionnaires such as the "State-Trait Anxiety Inventory" while physiological responses are measured via heart rate, blood pressure, cortisol and salivary IgA samples (Knight \& Rickard, 2001).

Hanser's (1988) article provides a base of the literature for analysing the measurement of anxiety related to music listening up to the year 1988. The author concluded that when measuring the effects of music on anxiety the use of physiological measurements was inconclusive and hoped that the means of measuring these variables would improve. Hanser(1988) preferred the use of behavioural observations and psychological measurement techniques. Biley's (2000) literature review also confirms that the results of the measurement of physiological variables as an indicator of anxiety appears to be least conclusive with conflicting results being obtained.

Due to this lack of consistent research about the effects of music on physiological variables, Knight and Rickard (2001) researched the robustness of using physiological variables to measure anxiety. They carried out an experimental study where the participants were subjected to a cognitive stressor. One group had music playing in the background while the other had no music. The results showed that exposure to the music prevented the significant increases in subjective anxiety, systolic blood pressure and heart rate caused by a cognitive stressor. The music piece also attenuated diastolic blood pressure and salivary IgA levels, independent of a stress response. The results are said to provide experimental support for claims that music is an effective anxiolytic treatment.

Ferrer's (2007) study of music therapy with clients undergoing chemotherapy treatment showed statistically significant improvement for the experimental group on the physiological measures of anxiety and diastolic blood pressure, however there were no significant differences for heart rate and systolic blood pressure. The author explains that the possible lack of consistent results for the physiological measures could be due to some subjects having received blood pressure medication prior to the beginning of chemotherapy treatment or undergoing intravenous starts during the intervention or that patients in the music group often clapped, sang along or tapped their feet which may have altered cardiac activity. 
The above article by Knight and Rickard (2001) does suggest the effectiveness of physiological measures, though this study was conducted in an experimental setting. A more realistic comparison for the present study would be the research by Ferrer (2007) since it occurred within a hospital setting. This study demonstrates that the addition of medication and other factors in hospitals may result in inaccurate physiological results. Hanser (1988) points out that when the listener is in a state of stress, their reaction is further complicated by the physiological responses to stress interacting with responses due to factors such as medication. Therefore Hanser (1988) indicates that it is not possible to elucidate the precise responses that would be expected in a music therapy stress reduction program.

\subsubsection{Psychological Measures of Anxiety}

Kabacoff, Segal, Hersen and Van Hasselt (1997) identified that for older persons, to avoid the fatigue effects common in long test batteries and structured interviews, test instruments that can be quickly administered and easily completed are particularly desirable. Correspondingly the authors identify that the most commonly used self-report measures of anxiety are the Beck Anxiety Inventory (BAI; Beck \& Steer, 1990) and the State-Trait Anxiety Inventory (Spielberger et al., 1983).

The Beck Anxiety Inventory (BAI) is a 21 item Likert scale self-report questionnaire measuring common symptoms of clinical anxiety, such as nervousness and fear of losing control (Kabacoff et al., 1997). Respondents indicate the degree to which they are bothered by each symptom. Each symptom is rated on a four-point scale ranging from zero (not at all) to three (severely, I could barely stand it), and the total scores can range from zero to 63, with higher scores corresponding to higher levels of anxiety. 13 items assess physiological symptoms, five describe cognitive aspects, and three represent both somatic and cognitive symptoms. However, the BAI measures the anxiety present in a week for the client. Thus this would represent the long-term anxiety for a client. It is unfeasible to assume that a single session of music therapy will affect the long-term anxiety of a client. However, it is hoped that music therapy will result in a reduction of the immediate (current) anxiety of a client.

A Gregory (2000) that investigated the application of test instruments in music therapy research used by "Journal of Music Therapy" authors from 1984 to 1997. The research 
identified 92 out of the 220 articles published during this period that used test instruments. Of these, the State Trait Anxiety Inventory (STAI) was the most frequently used and functioned as a dependant measure by nine researchers with eight different populations. The State Trait Anxiety Inventory (STAI) is a 40-item Likert scale that assesses separate dimensions of "state" anxiety (items 1-20) as well as "trait" anxiety (items 21-40) (Spielberger et al., 1983). The state anxiety represents the current anxiety state of an individual while the trait anxiety represents the longer-term anxiety traits of an individual. Kvaal, Ingun, Nordhus and Engedal (2005) carried out a study to assess whether the state part of the STAI was useful as a case-finding instrument of mental disorders in geriatric patients. The study included 70 participants who were nondemented geriatric inpatients in stable clinical condition. The mean age was 83.3 years with a range of 64 to 96 years. The conclusion was that the STAI state scale was a useful instrument for detecting a variety of mental disorders in older people. Therefore the STAI presents as a valid measure for this client group.

\subsection{Literature Review Summary}

The key findings of the literature review are summarised below:

- There is a paucity of quantitative research and a range of practical difficulties experienced by researchers conducting studies in psychiatric settings.

- Single session interventions where clients act as their own control with pre- and post-test measurement presents as a feasible research design to minimise the influence of the practical difficulties experienced in conducting research in psychiatric settings.

- Anxiety is the most commonly measured research variable for single session music therapy intervention studies.

- Research studies indicate that music therapy intervention causes a reduction in anxiety across various client groups.

- Psychological rather than physiological measurement tools are preferred within hospital settings due to patient medication acting as a confounding variable for physiological measurement.

- There is a wider use of the "State Trait Anxiety Inventory" than other measurement tools for the measurement of anxiety in music therapy research. 


\subsection{Hypothesis}

Music therapy will be more effective than reminiscence therapy $(\mathrm{p}=<0.5)$ in reducing anxiety in older persons with psychiatric disorders, as measured by the state part of the "State Trait Anxiety Inventory." 


\section{Method}

\subsection{Rationale for the Research Decisions}

The needs of the clients were the primary factor in determining the research decisions for this study. These research decisions were further informed and shaped by results and ideas from previous research as outlined in the previous chapter of the thesis reviewing the literature. This section outlines the personal views of this researcher to explain the rationale for the research decisions.

Based upon the practicalities of obtaining staff and a secure environment to carry out research, the ward staff and I felt that having the research based within the hospital would be more feasible than within the community. Therefore, the decision was made to limit and base the research within the fifteen-bed inpatient unit ${ }^{2}$.

Health-related environments have traditionally relied on quantitative rather than qualitative studies to determine the effectiveness of various interventions. (However attitudes about the relevance of qualitative studies for complex issues have begun to change in recent years. ${ }^{3}$ ) Given that this research was being carried out within the health sector and the first experience of music therapy for this unit, I felt that it would be useful to carry out a quantitative, rather than qualitative research for this current project. Positive findings from a quantitative research study, based on outcomes for the clients, could help evaluate the use of music therapy for older persons with psychiatric disorders.

In the in-patient ward, the clients were usually admitted for a maximum of three weeks. Given conditions such as medication and other medical and psychological interventions, realistically, clients could only be expected to attend a single music therapy session. The literature review also indicated that single session interventions minimise the influence of confounding variables in research in psychiatric settings. Therefore, we decided that

\footnotetext{
${ }^{2}$ Subsequent difficulties with recruitment necessitated drawing on the community clients as participants. This will be discussed further in the Methods and Results sections.

${ }^{3}$ A series of articles in the British Medical Journal in 2008 give strong justification for the place of qualitative research in the medical environment and encourages medical practitioners to understand it better. For example: Kuper, A., Reeves, S., \& Levinson, W. (2008). Qualitative Research: An introduction to reading and appraising qualitative research. British Medical Journal, 337(16 August 2008), 404-409.
} 
the most practical and feasible option for this current study would be to study the effects of single sessions of music therapy for this client group.

Within the music therapy group sessions on the ward, I noticed that typically clients would appear to smile more, be less agitated and exhibit improved co-operation and communication. Often people would come on to the ward after an emergency where their mental health had deteriorated and/or they were not coping at home. Regularly they were distressed and confused about a hospital admission. The hospital also seemed different and unfamiliar as compared to their home or rest-home. I felt that music therapy was a positive influence on the clients. Here are some examples, which, in the interest of client confidentiality, are not real people but are gleaned from genuine clinical experiences on the ward in the course of my 9 month placement.

\section{Case Study 1:}

Jenny, a 68 year old client, had been diagnosed with clinical depression. She has spent the morning sleeping in her bed since she said she was too depressed to interact socially. When she heard about the music therapy session, she said she liked music and would give it a try. As the music therapy session progressed, she began to sing when she heard songs familiar to her. She then began to talk about her past experiences and share her life journey with group. She became increasingly animated and laughed, smiled and joked with the other group members. Following the session, she was willing to mingle in the main lounge with the other patients and staff rather than return to her room. The music therapy session appeared to offer Jenny the familiar language of music and song as a basis to begin relating socially. It also seemed to encourage sharing of experiences and, through this process reduced her social isolation.

\section{Case Study 2:}

John was a 72 year old man diagnosed with Generalised Anxiety Disorder. On the ward he seemed constantly concerned with issues about his life. John initially appeared restless during the session. He tended to look around the room and outside the window. When the group was introduced to the instruments, he seemed intrigued by the ocean drum. This is an instrument with a large round drum frame containing small beads that creates a sound like the ocean. During the free improvisation that followed, John appeared to be engrossed in sounding the ocean drum and exploring the various sounds 
it created. The improvisation lasted about 10 minutes, during which time John's main focus was the ocean drum. At the end of the improvisation, he said that the sounds created reminded him of the ocean. He said that he used to live near the sea and missed the life he had had when he lived there. For the rest of the session, John appeared to be more focussed on the session and laughed and seemed interested in comments and music of other group members. When leaving the session, John got into a conversation about the sea with another group member. Half an hour after the session, he was noticed still engrossed in the conversation with the other group member. The music created by the musical instruments seemed to help John lift out of his state of anxiety. It appeared to help him reflect on a happy period of life in his past. This correspondingly helped him focus on the session and seemed to reduce his anxiety about the future.

\section{Case Study 3:}

Jane was a 68 year old woman experiencing auditory persecutory hallucinations. On the ward she tended constantly to talk back to the auditory hallucinations. At the start of the session, she often interrupted the music to tell the group what the "voices" were saying to her and seemed to be distressed. Jane was encouraged to focus on the music. She said that the band "Abba" was her favourite. We sang some Abba songs for her. During the singing of these songs, her responses to the "voices" tended to reduce. She was also encouraged to engage within active music making with the other patients in the room. For Jane, the music therapy sessions appeared to offer an alternate focus to the auditory hallucinations. As a follow up it was recommended that Jane could be supplied with Abba CD's in her room. During the week, Jane was noted to be singing in her room when she needed respite from the auditory hallucinations.

Other staff and myself felt, from a clinical perspective, that reduction in agitation/increased pleasure would be a valuable contribution for music therapy to improve clients' well-being on the ward. In planning research it seemed that changes in, and particularly reduction of anxiety, might relate to these clinical goals and could practically and ethically be measured in this context with the resources I had available to me. Therefore, the proposed research variable was chosen.

The music therapy sessions at the hospital were an open group format. It was open to all clients and not limited to patients with an anxiety diagnosis. Conversations with staff 
and personal observations indicated the most of the clients demonstrated some degree of anxiety even if it was not part of their diagnosis. This may have been in relation to being within an acute state of their illness. Therefore it was decided to study anxiety as a general condition rather than limit the study specifically to clients with a diagnosis of anxiety. A suggestion by Charles Spielberger, the author of the STAI (See Appendix A) was to administer the Trait anxiety scale to the participants prior to commencing the study to allow an evaluation of the differential effects of music therapy on S-Anxiety for patients who are high and low in T-Anxiety. However, given the staffing restrictions of a student project and the considerations of administering an additional scale, it was decided to not implement this measure for this current study.

Physiological measurements were felt to be intrusive to the clients who are faced with a battery of testing while at the hospital. Minimising these tests as part of the research was an important consideration in choosing psychological rather than physiological measurements for this study. In addition, the literature search also identified that physiological variables are likely to be influenced by other medication and thus psychological measurement may be preferred.

The State Trait Anxiety Inventory (STAI) was chosen as the measurement tool since dialogue with psychologists on the ward and prior research identified it as the main standardised tool to measure the effects of single therapy sessions. In addition, Charles Spielberger, the author of the STAI was contacted regarding the suitability of this tool for this client group. He commented that he believed that this tool would be an appropriate measure for assessing change in state anxiety before and after the interventions (Spielberger, 2008) (See Appendix A).

The section below represents the ideal methodology that was chosen based upon the decisions discussed above. However, during the data collection phase, there were practical difficulties that resulted in some deviations from this method outlined for a few participants. These deviations are discussed in section 3.4.2 within this methods section. 


\subsection{Sample}

\subsubsection{Total Population}

The sample population was chosen from the acute inpatient ward. This sample consisted of males and females aged 65 years and over. The participants potentially belonged to any ethnic group.

The exclusion criterion was:

- Patients for whom the clinical staff felt that music therapy was inappropriate based on clinical grounds.

- Patients for whom it was felt cognitive difficulties would create challenges in understanding and answering the "State Trait Anxiety Inventory" questionnaire.

All suitable clients were approached until the required sample size was achieved.

The clients were provided an information sheet about the study. There were two versions of the information sheet due to the acute state of the clients. One version was a single page "Summary Sheet" that listed in bullet points in a large font the summary of the research and what it required of the participants (See Appendix B). Once the client consulted this sheet and if they wished to go ahead, they were given and explained the "Information Sheet" that contained detailed information about the study (See Appendix C). If the clients agreed to participate in the study, they were given the "Consent Form" to read and sign (See Appendix D). To minimise coercion, the occupational therapy staff without the presence of the researcher/student music therapist carried out this process.

\subsubsection{Sample Size}

The sample size for this study was agreed as ten research participants. This was based on advice from a statistician. Please refer to Appendix E for the statistician's report for the sample size analysis. An important consideration for this sample size was that the project was restricted by the time and resource constraints of a university educational course. However, the statistician reported that this chosen sample size of ten participants would enable potentially large treatment effects to be examined, if they occurred. 


\subsection{Interventions}

The following are the intervention details for each participant:

- One 30 minute group music therapy session

- One 30 minute travel group (reminiscence therapy) intervention. This was designed to act as the control group

- Both sessions were designed to be carried out by the researcher/student music therapist and an occupational therapist. The occupational therapy team that formed a part of the "Mental Health of Older Persons" service provided support for the project.

- The testing site for both interventions was proposed to be the meeting room on the ward. This provided a private space to engage in therapy with minimal external distractions.

\subsubsection{A Typical Music Therapy Intervention}

The music therapy session design focussed on the issues highlighted within the literature review in chapter two. These included concepts such as the need for focus and direction by the therapist within single session interventions to ensure the client's therapeutic safety and goals are met. In addition, to aid reduction of anxiety client preferences were considered rather than relying on a prescriptive style of music

The session usually started with a verbal welcome to the clients, explaining that this was a private therapeutic space and that if they felt the need to leave the session they could inform one of the staff who would assist them back to the ward. The therapist then usually sang the song, "Welcome to My World" as an introductory song, inviting the clients to either join in, or just listen if they wish to. The instruments provided during the music therapy sessions were the ocean drum, rain stick, triangle, bongo, caxixi, wind-chimes, bells and egg shakers. While the clients explored the instruments, the therapist would provide an improvised musical backing to support the resulting group improvisation. At the end of the improvisation, the clients were invited to, or volunteered recollections or associations stimulated by the music or the instruments. This was usually followed by further improvisations or songs based on the verbal reflections or the cultural preferences indicated by the clients. Towards the end of the session, the therapist aimed to re-orientate the clients to the present and ended with a song such as "What a Wonderful World" or "You are my Sunshine." Although the 
above description is of a typical session, every session had different clients that correspondingly created a different dynamic that the music therapist had to use as a basis to structure the session. ${ }^{4}$

\subsubsection{A Typical Control Group (Reminiscence Therapy Intervention)}

The control group model selected was an alternative treatment control group. This group was designed to be a typical non-music intervention intended to affect the dependant variable in a similar manner to the music treatment. It was felt that this type of control group would provide the most effective comparison to the music therapy group.

The control group was implemented in conjunction with the occupational therapy team on the ward. It was decided to choose a reminiscence therapy group in the form of a travel group since the occupational therapy team had anecdotal feedback of its effectiveness in helping reduce anxiety along with its pre-existing resources for its implementation. The travel group acted as a reminiscence therapy group that stimulated verbal conversation through information, pictures and food from a given country.

\subsection{Data Collection Method}

- The data collection was via the state part of a "State Trait Anxiety Inventory" (See Appendix F).

- It was administered by the occupational therapy staff without the presence of the researcher (student music therapist).

- The clients acted as their own control.

- The measurement tool was administered a total of four times:

1. pre- music therapy

2. post- music therapy

3. pre- control group

4. post- control group

- Ideally, the order of interventions would have been randomisation by the use of a program such as Microsoft Excel. Appendix E provides the statistician's indicated ideal method of randomisation. However given the perceived

\footnotetext{
${ }^{4}$ The individual sessions in rest homes settings followed a similar structure to these group settings, though the musical style selection was more catered to the individual's preferences.
} 
practicalities of client availability, the order of delivery of the interventions was dependent on the client availability. Therefore for this study, randomisation was considered to be provided by client availability.

\subsubsection{The State Trait Anxiety Inventory}

The State Trait Anxiety Inventory (STAI) is a 40-item Likert scale that assesses separate dimensions of "state" anxiety (items 1-20) as well as "trait" anxiety (items 2140) (Spielberger et al., 1983). The state anxiety represents the current anxiety state of an individual while the trait anxiety represents the longer-term anxiety traits of an individual. Each item is rated on a 4-point intensity scale. The total score can lie between 20 and 80. A higher score indicates a higher anxiety. The state anxiety scale has demonstrated construct validity (Spielberger et al., 1983). Construct validity is the support for the intended interpretation of the variables (Wikipedia, 2009). It also has a high Cronbach alpha co-efficient for the state-anxiety scale with an overall median coefficient of 0.92 (Spielberger et al., 1983). Cronbach's $\alpha$ is a coefficient of consistency and measures how well a set of variables or items (STAI items) measures a single, unidimensional latent construct (anxiety) (Wikipedia, 2008). Appendix F contains a copy of the state part of the STAI.

\subsubsection{Practical Challenges to the Planned Method}

Difficulties with recruiting clients who presented with the cognitive ability to complete the STAI resulted in a shortage of appropriate participants from the acute inpatient ward. Therefore, additional participants were recruited from the community to meet the required sample size, due to research timelines. The methodological deviations for these participants are listed below.

- The sample population was clients who were serviced by the community team. These were clients who were older persons with psychiatric disorders. They were not in an acute stage of their illness and therefore did not require being within the inpatient ward, though their condition still warranted the need for support from the hospital community team.

- The testing site was the client's room within the rest home.

- The music therapy intervention was administered within an individual rather than group setting. 
- The control intervention was a verbal discussion with the individual about anxiety management rather than a travel group. This was because it was administered by the occupational therapy team as part of a standard anxiety management session rather than the music therapy student due to time constraint availability of the participants

Further details about these deviations are presented within the results section.

\subsection{Ethical Issues}

\subsubsection{Ethical Approval}

The project has the following approvals:

- Approval from the Northern X Regional Ethics Committee, New Zealand (NTX/08/08/055) (See Appendix G).

- Clinical board approval from the "xxxxx District Health Board."

- Scientific assessment and approval by an independent review of the academic committee of the New Zealand School of Music (See Appendix H).

\subsubsection{Minimisation of Harm}

- The researcher was also the treatment provider (student music therapist). This presented the possibility of coercion and a conflict of interest. To minimise this risk, the occupational therapy staff did the recruitment process of obtaining consent and administrating the test instrument.

- The research was designed to minimise its impact on standard music therapy treatment for the clients. Therefore, the tests were administered pre- and postthe sessions rather than data being gathered during the sessions.

- Possible psychological risks to the participants could have occurred through the process of completing the STAI. To minimise this possible harm the test instrument used was a standardised instrument that had been used in prior research and found to be effective in measuring anxiety with this client group. 
- The music therapist monitored individuals during the session for any possible harmful effects. A debriefing meeting occurred with the staff conducting the research after each intervention and its consequent data collection. This debriefing helped identify and take action on any possible issues that arose during the session and the data collection process.

- Since the clients were in an acute state the possibility of medical emergencies arising during the sessions was high. However, if an emergency did occur, since the research occurred within the clinical settings, the team of professionals that care for the patients could easily be approached.

\subsubsection{Privacy and Confidentiality}

The following processes were implemented to ensure privacy and confidentiality for the clients.

- The data was stored securely at the facility during the data collection period. At this stage only the researcher and the occupational therapy staff assisting with the project had access to the data.

- After the completion of the project, the data will be stored in a locked cupboard at the New Zealand School of Music for a period of ten years. At this stage, only the researcher and the research supervisor will have access to the data.

\subsubsection{Cultural Issues}

Cultural advice and approval was sought was from the relevant persons and professional bodies to ensure that this research would respect and address relevant cultural issues.

- The, "Maaori Research Review Committee" of the "Xxxxxx District Health Board" has approved the project.

- During the initial project planning, project design and data collection Maori cultural consultation was sought from the Maori Kaumatua Kuia at the Marae for the Tangata Whaiora and Whanau of the xxxxx District Health Board mental health services.

- During the course of the project, assistance was sought from the cultural team and the ward staff at the hospital when emerging cultural issues arose. 


\section{Results}

\subsection{Summary of the Results}

The analysis provided the following main statistical results.

- The music therapy intervention significantly reduced the anxiety level $[\mathrm{t}(8)=4.626, \mathrm{p}<0.0017]$ as reported by the state part of the "State Trait Anxiety Inventory" when compared to the control group.

- There is no evidence for a significant carryover effect since the baselines prior to each intervention did not difference significantly [ $t(8)=0.6315, \mathrm{p}<0.55]$.

Thus the hypothesis is supported that there is a statistically significant difference at $p=<0.5$ between the impact of single sessions of music therapy as compared to the control intervention in the reduction of anxiety levels for older persons with psychiatric disorders as measured by the state part of the "State Trait Anxiety Inventory."

\subsection{Data from the Measurement Tool}

Due to time constraints and practical considerations, nine rather than the projected 10 participants were recruited for this research study. The results for the state part of the "State Trait Anxiety Inventory (STAI)" for the participants are listed in Table 1. Figure 2 is a graphical representation of the participant's scores. The total score for the STAI ranges from 20 to 80 . A higher score indicates a higher anxiety.

Table 1: STAI Results

\begin{tabular}{|c|c|c|c|c|c|c|c|c|}
\hline Participant & \multicolumn{2}{|c|}{ Raw Scores } & \multicolumn{2}{c|}{$\begin{array}{c}\text { Difference between } \\
\text { post \& pre MT scores }\end{array}$} & \multicolumn{2}{c|}{ Raw Scores } & \multicolumn{2}{c|}{$\begin{array}{c}\text { Difference between post } \\
\text { \& pre ctrl scores }\end{array}$} \\
\cline { 2 - 9 } & $\begin{array}{c}\text { Pre- } \\
\text { MT }\end{array}$ & $\begin{array}{c}\text { Post- } \\
\text { MT }\end{array}$ & $\begin{array}{c}\text { Unit } \\
\text { Change }\end{array}$ & $\begin{array}{c}\text { Percentage } \\
\text { Change }\end{array}$ & $\begin{array}{c}\text { Pre- } \\
\text { ctrl }\end{array}$ & $\begin{array}{c}\text { Post- } \\
\text { ctrl }\end{array}$ & $\begin{array}{c}\text { Unit } \\
\text { Change }\end{array}$ & $\begin{array}{c}\text { Percentage } \\
\text { Change }\end{array}$ \\
\hline 1 & 25 & 27 & 2 & $3 \%$ & 21 & 27 & 6 & $10 \%$ \\
\hline 2 & 41 & 25 & -16 & $-27 \%$ & 40 & 39 & -1 & $-2 \%$ \\
\hline 3 & 74 & 60 & -14 & $-23 \%$ & 67 & 71 & 4 & $7 \%$ \\
\hline 4 & 38 & 25 & -13 & $-22 \%$ & 34 & 35 & 1 & $2 \%$ \\
\hline 5 & 50 & 31 & -19 & $-32 \%$ & 50 & 48 & -2 & $-3 \%$ \\
\hline 6 & 40 & 29 & -11 & $-18 \%$ & 42 & 40 & -2 & $-3 \%$ \\
\hline 7 & 32 & 31 & -1 & $-2 \%$ & 20 & 23 & 3 & $5 \%$ \\
\hline 8 & 36 & 24 & -12 & $-20 \%$ & 36 & 36 & 0 & $0 \%$ \\
\hline 9 & 20 & 23 & 3 & $5 \%$ & 22 & 24 & 2 & $3 \%$ \\
\hline Mean & 39.56 & 30.56 & -9.00 & $-15 \%$ & 36.89 & 38.11 & 1.22 & $2 \%$ \\
\hline
\end{tabular}

Notes for Table 1: MT=Music Therapy; ctrl=control

Figure 2: STAI Scores for Each Participant 


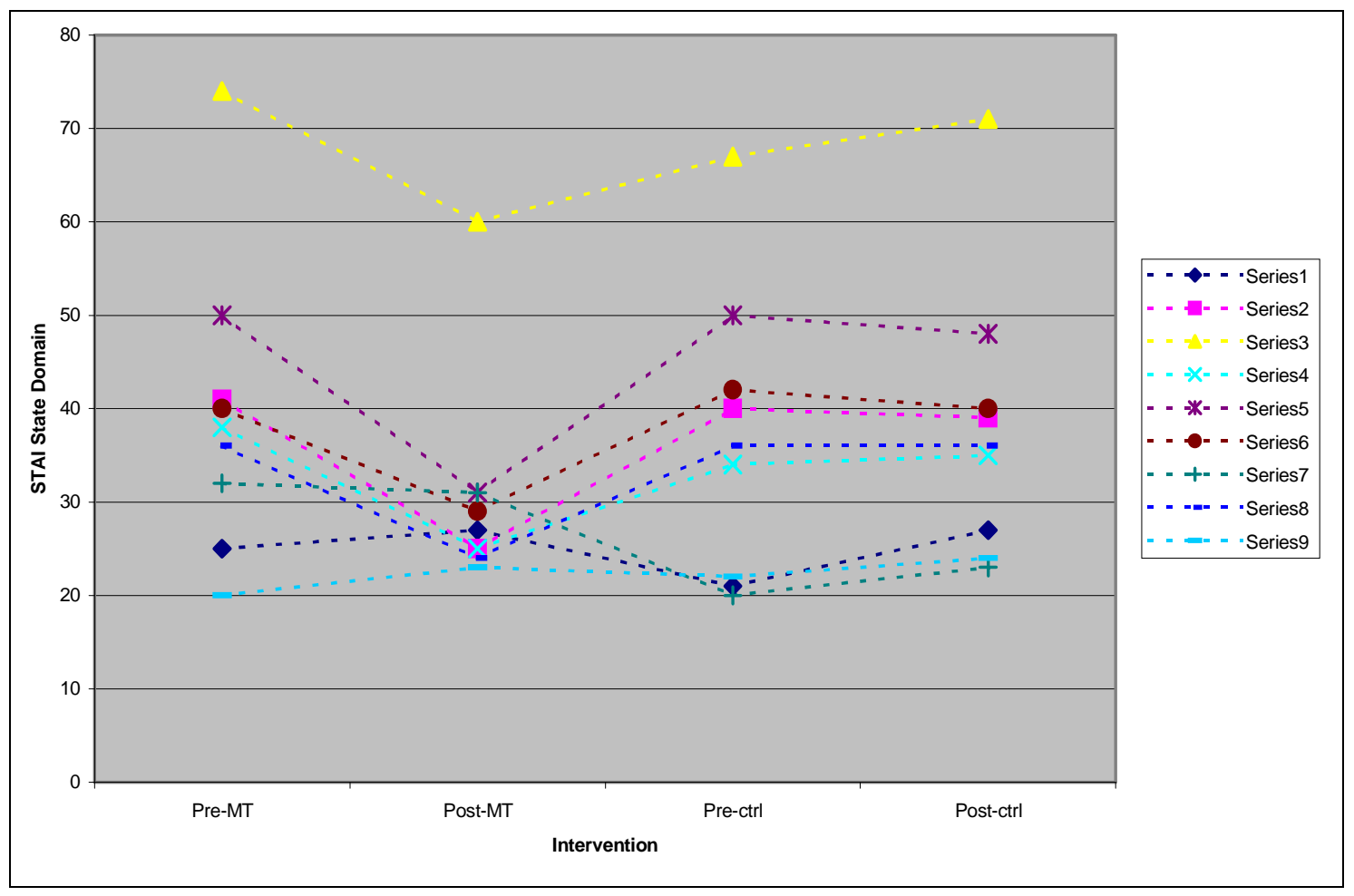




\subsection{Order of Interventions}

Table 2 : Order of Interventions

\begin{tabular}{|c|c|}
\hline Participant & Order of Interventions \\
\hline 1 & Music Therapy- Control \\
\hline 2 & Music Therapy- Control \\
\hline 3 & Control-Music Therapy \\
\hline 4 & Music Therapy- Control \\
\hline 5 & Music Therapy- Control \\
\hline 6 & Music Therapy- Control \\
\hline 7 & Music Therapy- Control \\
\hline 8 & Music Therapy- Control \\
\hline 9 & Music Therapy- Control \\
\hline
\end{tabular}

Table 2 lists the order in which the interventions were administered for each participant. It indicates that for all the participants except participant 3, the music therapy intervention was administered before the control intervention.

Due to the service being an acute in-patient service, for the purposes of the research, it was assumed that the clients would only be on the ward for a week. Therefore, both interventions were carried out within a week. The music therapy intervention was usually the first intervention carried out during the week. Since the clients were recruited during the week before the music therapy student's practicum day, the first intervention that the clients attended was usually music therapy. Client number 3 was not available when the music therapy intervention was administered for the week, and therefore the first intervention was the control group, followed by music therapy in the following week. 


\subsection{Main Results}

\subsubsection{Treatment Effects - Addressing the Hypothesis}

Table 3: Treatment Effects Calculations

\begin{tabular}{|c|c|}
\hline Number Of Values & 9 \\
\hline Minimum & -1.00 \\
\hline $25 \%$ Percentile & -4.00 \\
\hline Median & 12.00 \\
\hline $75 \%$ Percentile & 16.00 \\
\hline Maximum & 18.00 \\
\hline Mean & 10.22 \\
\hline Standard Deviation & 6.63 \\
\hline Standard Error & 2.21 \\
\hline Lower 95\% CI of Mean & 5.13 \\
\hline Upper $95 \%$ CI of Mean & 15.32 \\
\hline \multicolumn{2}{|c|}{ D'Agostino and Pearson's Normality Test } \\
\hline $\mathrm{K} 2$ & 1.12 \\
\hline $\mathrm{p}$ value & 0.57 \\
\hline $\begin{array}{l}\text { Passed Normality Test } \\
(\text { alpha=0.05)? }\end{array}$ & Yes \\
\hline $\mathrm{p}$ value summary & Ns \\
\hline \multicolumn{2}{|c|}{ Shapiro Wilk Normality Test } \\
\hline $\mathrm{W}$ & 0.93 \\
\hline $\mathrm{p}$ value & 0.46 \\
\hline $\begin{array}{l}\text { Passed Normality Test } \\
(\text { alpha }=0.05)\end{array}$ & Yes \\
\hline $\mathrm{p}$ value summary & ns \\
\hline \multicolumn{2}{|c|}{ One Sample t-test } \\
\hline Theoretical mean & 0.00 \\
\hline Actual Mean & 10.22 \\
\hline Discrepancy & -10.22 \\
\hline $95 \%$ CI of discrepancy & $\begin{array}{l}5.13 \text { to } \\
15.32 \\
\end{array}$ \\
\hline $\mathrm{t}, \mathrm{df}$ & $t=4.63, d f=8$ \\
\hline $\mathrm{p}$ value (two tailed) & $\mathrm{p}=0.0017$ \\
\hline Significant (alpha $=0.05) ?$ & Yes \\
\hline \multicolumn{2}{|c|}{ Wilcoxon Signed Rank Test } \\
\hline Theoretical Median & 0.00 \\
\hline Actual median & 12.00 \\
\hline Discrepancy & -12.00 \\
\hline Sum of signed ranks $(\mathrm{W})$ & 43.00 \\
\hline Sum of positive ranks & 44.00 \\
\hline
\end{tabular}


A statistician was employed to carry out a statistical analysis. The data were analysed using PRISM v5.0 (www.graphpad.com). The results obtained are summarised in Table 3.

For each of the participants the difference between post and pre the musical intervention was subtracted from the difference between the post and pre the control intervention. This formed the primary endpoint. This is represented in figure 3.

The median (50\% percentile) was 12.00 with $25 \%$ of the values lying below $-4.00(25 \%$ percentile) and $75 \%$ of the values lying above 16.00 (75\% percentile). The minimum value was -1.00 and the maximum value was 18.00 .

The mean (average) value was 10.22 with a standard deviation of 6.63 . The standard error of the mean which quantifies the precision of the mean and provides a measure of how far the sample mean is likely to be from the true population mean has a value of 2.21 (Graphpad, 2009). The 95\% confidence interval for this sample has a lower value of 5.13 and an upper value of 15.32 . This represents a $95 \%$ chance that the confidence interval of 5.13 to 15.32 contains the true mean value for the entire sample population for this study (Graphpad, 2009).

The data would ideally be analysed using a t-test. To carry out a parametric test, such as a t-test on a sample requires the assumption that the sampled data is being analysed from a population that follows a Gaussian (normal) bell-shaped distribution (Graphpad, 2009). Normality tests compute the probability that the data is consistent with a Gaussian (normal) distribution.

For this study a D'Agostino-Pearson normality test was used to compute the normality of the sample. A large $\mathrm{p}$ value indicates that the data is consistent with a Gaussian distribution. The data passed the normality test with a $\mathrm{p}$ value of 0.5726 , which was greater than the alpha value of 0.05 . This indicates that a t-test could be performed on the data since the data is assumed to be consistent with a Gaussian (normal) distribution. To reinforce the normality of the distribution, a Shapiro-Wilks Normality test also was carried out. The data passed this normality test with a $\mathrm{p}$ value of 0.46 , which was greater than the alpha value of 0.05 
A one-sample two-tailed t-test was carried out on the data. This test compared the sample mean against a theoretical mean of zero. The $p$ value obtained, answers the question that if the data were sampled from a Gaussian population with a mean equal to the theoretical value, what is the chance of randomly selecting $N$ (9) data points and finding a mean as far (or further) from the theoretical value as observed in this study (Graphpad, 2009). The $\mathrm{p}$ value obtained for this study was 0.0017. $\mathrm{p}<0.05$ was considered to be statistically significant. Therefore the results support the hypothesis and it can be concluded that it is unlikely that the discrepancy observed between sample mean and theoretical mean is due to a coincidence arising from random sampling.

Given the small sample size, there may have been the possibility that the normality test provided an inaccurate result. Therefore, to reinforce the results, a non-parametric "Wilcox Signed Rank Test" was also carried out. This test does not require the data to follow a Gaussian distribution. Instead, the values are ranked from low to high, and the analyses are based on the distribution of ranks. This test compares the sample median of the study against a theoretical median (Graphpad, 2009). This test presents the results as the sum of the signed ranks. If the data is said to be sampled from a population with the theoretical mean, W could be expected to be near zero. If W (the sum of signed ranks) is far from zero, the $p$ value will be small. Since the value obtained for $W$ is 43 , it considered to be far from zero and therefore has a small $p$ value. As the $p$ value is small, it is said that the idea that the difference is due to chance can be rejected and instead it can be concluded that the population has a median distinct from the theoretical value. Thus this test reinforces the validity of the results. 
Figure 3: Difference (control-music) in Change (pre-post) in State Domain

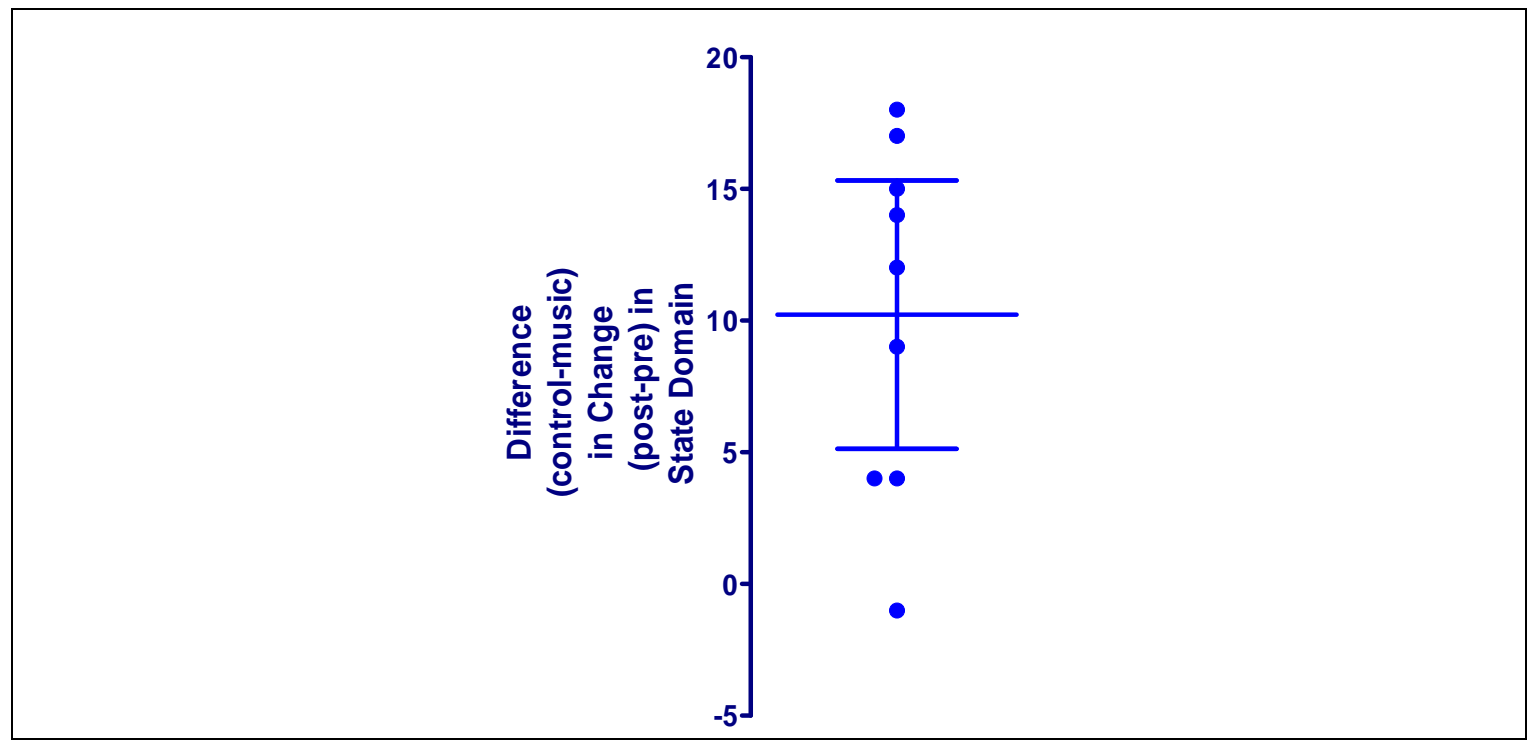




\subsubsection{Carry-Over Effects}

Table 4: Carry Over Effects Calculations

\begin{tabular}{|c|c|}
\hline Number Of Values & 9 \\
\hline Minimum & -7.00 \\
\hline $25 \%$ Percentile & -2.00 \\
\hline Median & 0.00 \\
\hline $75 \%$ Percentile & 4.00 \\
\hline Maximum & 12.00 \\
\hline Mean & 1.11 \\
\hline Standard Deviation & 5.28 \\
\hline Standard Error & 1.76 \\
\hline Lower $95 \%$ CI of Mean & -2.95 \\
\hline Upper 95\% CI of Mean & 5.17 \\
\hline \multicolumn{2}{|c|}{ D'Agostino and Pearson's Normality Test } \\
\hline $\mathrm{K} 2$ & 3.07 \\
\hline $\mathrm{p}$ value & 0.22 \\
\hline Passed Normality Test (alpha $=0.05) ?$ & Yes \\
\hline $\mathrm{P}$ value summary & Ns \\
\hline \multicolumn{2}{|c|}{ Shapiro Wilk Normality Test } \\
\hline $\mathrm{W}$ & 0.93 \\
\hline $\mathrm{P}$ value & 0.50 \\
\hline Passed Normality Test (alpha $=0.05$ ) & Yes \\
\hline $\mathrm{P}$ value summary & Ns \\
\hline \multicolumn{2}{|l|}{ One Sample t-test } \\
\hline Theoretical mean & 0.00 \\
\hline Actual Mean & 1.11 \\
\hline Discrepancy & -1.11 \\
\hline $95 \%$ CI of discrepancy & $\begin{array}{l}-2.95 \text { to } \\
5.17\end{array}$ \\
\hline $\mathrm{t}, \mathrm{df}$ & $\begin{array}{l}\mathrm{t}=0.63 \\
\mathrm{df}=8\end{array}$ \\
\hline p value (two tailed) & 0.55 \\
\hline Significant (alpha $=0.05)$ ? & Yes \\
\hline \multicolumn{2}{|c|}{ Wilcoxon Signed Rank Test } \\
\hline Theoretical Median & 0.00 \\
\hline Actual median & 0.00 \\
\hline Discrepancy & 0.00 \\
\hline Sum of signed ranks $(\mathrm{W})$ & 6.00 \\
\hline Sum of positive ranks & 17.00 \\
\hline
\end{tabular}

To assess carry-over effects, the difference in values pre-music and pre-control interventions were compared. Table 4 lists the carry-over effects calculations and figure 4 represents the difference in scores between pre-control and pre-music therapy that were used to carry out these calculations. Carrying out a similar analysis as for the treatment effects, the mean obtained was 1.11 with a lower confidence interval of -2.95 
and an upper confidence interval of 5.17. The data passed the D-Agostino and Pearson Omnibus Normality test and the Shapiro-Wilk Normality test. Consequently a one sample two tailed test was carried out with a result of a $\mathrm{p}$ value of 0.55 . A p-value smaller than 0.05 was considered to be significant. Since the value obtained was greater than 0.05 , it can be concluded that there was no significant carry-over effects.

Figure 4: Difference In Scores Between Pre-Music Therapy And Pre-Control For Each Participant

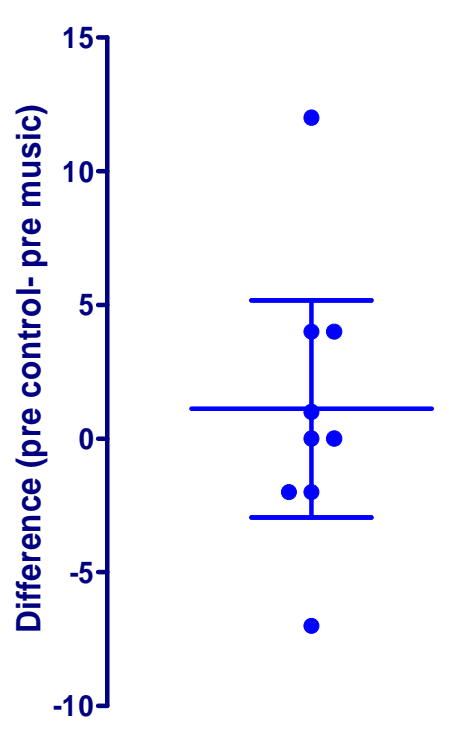




\subsection{Secondary Results}

\subsubsection{Reliability of the Measurement Tool}

Table 5: Comparison Of Pre-Intervention Scores For Each Participant

\begin{tabular}{|c|c|c|c|c|}
\hline Participant & Pre-music therapy & \multirow{2}{*}{ Pre-control } & \multicolumn{2}{|c|}{ Variation of State Anxiety } \\
\cline { 3 - 5 } & & & Unit change & Percentage change \\
\hline 1 & 25 & 21 & 4 & $7 \%$ \\
\hline 2 & 41 & 40 & 7 & $2 \%$ \\
\hline 3 & 74 & 67 & 4 & $12 \%$ \\
\hline 4 & 38 & 34 & 0 & $7 \%$ \\
\hline 5 & 50 & 50 & 2 & $3 \%$ \\
\hline 6 & 40 & 42 & 12 & $20 \%$ \\
\hline 7 & 32 & 20 & 0 & $0 \%$ \\
\hline 8 & 36 & 36 & 2 & $3 \%$ \\
\hline 9 & 20 & 22 & 3.56 & $6 \%$ \\
\hline Mean & 39.56 & 36.89 & & \\
\hline
\end{tabular}

Table 5 indicates that the nine pre-music therapy scores have a mean value of 39.56 and the nine pre-control group scores have a mean value of 36.89. Thus the overall mean score pre-intervention for both groups was 38.22. The outlier of participant 3 that is graphically displayed in Figure 2 would affect this mean value. Without including participant 3, the overall mean score pre-intervention would have been 34.19. Normative or clinically significant scores for this client group were not available from the STAI manual. However, the results could be compared to research into the use of the STAI with 70 non-demented geriatric patients by Kvaal et al. (2005). The mean score for the state part of the STAI was 56.3 units for that study. This mean of 56.3 is higher than the mean of 38.22 obtained for this current study. The lower mean value obtained in this current study could be due to a smaller sample size or a reflection of the ability of the ward to help this client group maintain a relatively low level of state anxiety.

The variation in the state anxiety scores obtained between the pre-music intervention and pre-control intervention for all the participants has a mean value of 3.56 units. This difference of $6 \%$ could represent a relatively low variation in pre-intervention scores. It indicates that the participants tended to exhibit a relatively stable state of anxiety over time and thus could reinforce the reliability of this test instrument for these participants. 


\subsubsection{Change in Test Scores for Each Participant}

Table 6: Change in Scores for Each Participant

\begin{tabular}{|c|c|c|c|c|c|}
\hline \multirow[t]{3}{*}{ Participants } & \multicolumn{4}{|c|}{ Difference between scores post- and pre- the interventions } & \multirow{3}{*}{$\begin{array}{l}\text { Relative decrease in score } \\
\text { for music therapy compared } \\
\text { to the control intervention }\end{array}$} \\
\hline & \multicolumn{2}{|c|}{ Music Therapy Intervention } & \multicolumn{2}{|c|}{ Control Intervention } & \\
\hline & Unit Change & $\begin{array}{c}\text { Percentage } \\
\text { Change }\end{array}$ & Unit Change & $\begin{array}{c}\text { Percentage } \\
\text { Change }\end{array}$ & \\
\hline 1 & 2 & $3 \%$ & 6 & $10 \%$ & $-7 \%$ \\
\hline 2 & -16 & $-27 \%$ & -1 & $-2 \%$ & $-25 \%$ \\
\hline 3 & -14 & $-23 \%$ & 4 & $7 \%$ & $-30 \%$ \\
\hline 4 & -13 & $-22 \%$ & 1 & $2 \%$ & $-23 \%$ \\
\hline 5 & -19 & $-32 \%$ & -2 & $-3 \%$ & $-28 \%$ \\
\hline 6 & -11 & $-18 \%$ & -2 & $-3 \%$ & $-15 \%$ \\
\hline 7 & -1 & $-2 \%$ & 3 & $5 \%$ & $-7 \%$ \\
\hline 8 & -12 & $-20 \%$ & 0 & $0 \%$ & $-20 \%$ \\
\hline 9 & 3 & $5 \%$ & 2 & $3 \%$ & $2 \%$ \\
\hline Mean & -9.00 & $-15 \%$ & 1.22 & $2 \%$ & $-17 \%$ \\
\hline
\end{tabular}

The following points can be noted from Table 6 and figure 5 .

- Music therapy resulted in a $17 \%$ greater decrease in anxiety as compared to the control intervention.

- Seven out of $9(78 \%)$ participants showed a decrease in anxiety after the music therapy intervention while only 3 out of $9(33 \%)$ showed a decrease in anxiety after the control intervention.

- The mean change in anxiety for the music therapy intervention was a reduction of 9 units (-15\%) while there was an increase of 1.22 units (2\%) in mean change in anxiety after the control intervention.

- The highest reduction in anxiety after the music therapy intervention was of 19 units $(-32 \%)$ while the highest reduction of anxiety after the control intervention was 2 units $(-3 \%)$.

- The highest increase in anxiety after music therapy was of 3 units (5\%) while the highest increase in anxiety after the control intervention was of 6 units (10\%). 
Figure 5: Change In Scores For Each Participant For Both Interventions

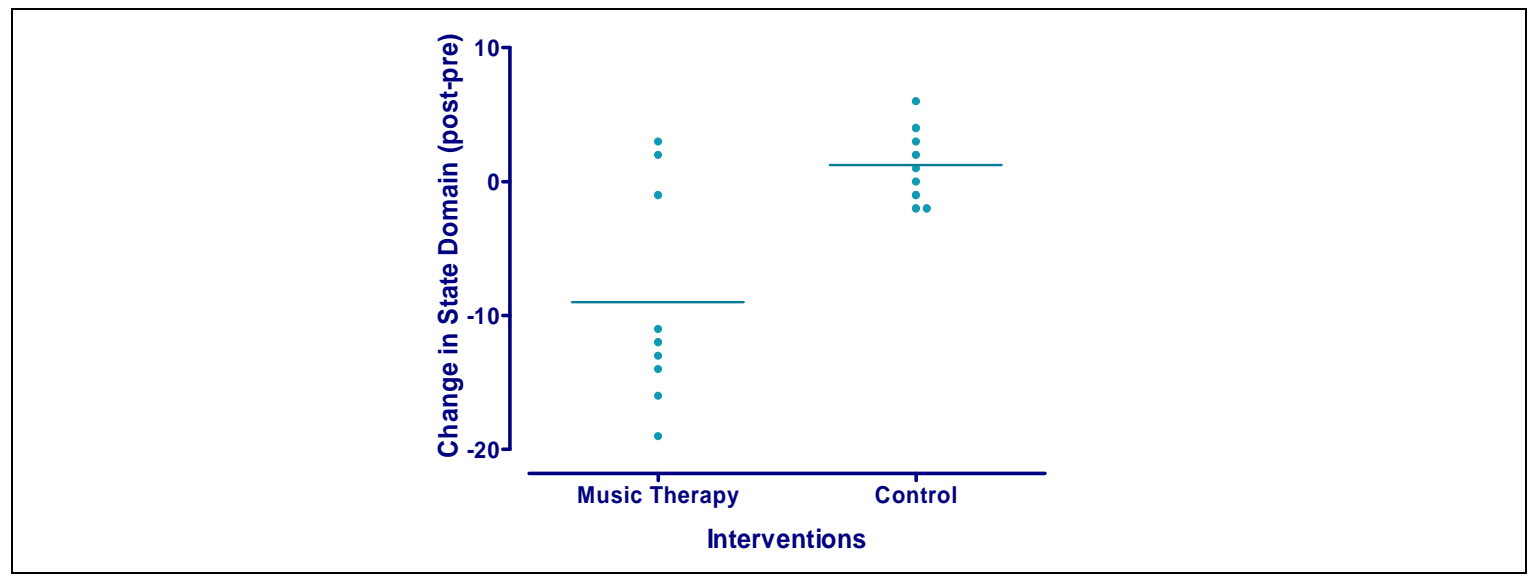

\subsection{Study Limitations}

Table 7: Deviations From the Proposed Research Design

\begin{tabular}{|c|c|c|c|c|c|c|}
\hline \multirow{2}{*}{ Participant } & \multicolumn{3}{|c|}{ Music Therapy } & \multicolumn{2}{c|}{ Control Intervention } \\
\cline { 2 - 7 } & $\begin{array}{c}\text { Type of } \\
\text { Intervention }\end{array}$ & $\begin{array}{c}\text { Testing } \\
\text { Location }\end{array}$ & $\begin{array}{c}\text { Type of } \\
\text { Setting }\end{array}$ & $\begin{array}{c}\text { Type of } \\
\text { Intervention }\end{array}$ & $\begin{array}{c}\text { Testing } \\
\text { Location }\end{array}$ & $\begin{array}{c}\text { Type of } \\
\text { Setting }\end{array}$ \\
\hline 1 & Music Therapy & Hospital & Group & Travel Group & Hospital & Group \\
\hline 2 & Music Therapy & Hospital & Group & Travel Group & Hospital & Group \\
\hline 3 & Music Therapy & Resthome & Individual & $\begin{array}{c}\text { Anxiety } \\
\text { management }\end{array}$ & Resthome & Individual \\
\hline $4^{*}$ & Music Therapy & Hospital & Group & Travel Group & Hospital & Group \\
\hline 5 & Music Therapy & Resthome & Individual & $\begin{array}{c}\text { Anxiety } \\
\text { Management }\end{array}$ & Resthome & Individual \\
\hline $6^{*}$ & Music Therapy & Hospital & Group & Travel Group & Hospital & Group \\
\hline 7 & Music Therapy & Hospital & Group & Travel Group & Hospital & Group \\
\hline 8 & Music Therapy & Resthome & Individual & $\begin{array}{c}\text { Anxiety } \\
\text { Management }\end{array}$ & Resthome & Group \\
\hline 9 & \multicolumn{7}{|l|}{ Music Therapy } & Hospital & Group & Travel Group & Hospital & Group \\
\hline * Participants 4 and 6 is the same participant who had the test administered twice & \multicolumn{5}{l}{} \\
\hline
\end{tabular}

The recruitment of participants from the acute unit was hampered due to the clients being acutely unwell and their cognitive impairment resulting in them being unable to complete the STAI. As a result, during the data collection phase it was felt that the required number of clients might not be obtainable within the given time frame. Therefore, as indicated in the methodology, it was decided to recruit participants from the community as well.

Three participants were recruited from the community. For these three participants, the research was carried out at the rest homes where they resided. Thus, the research intervention location was at their rest home, rather than in a hospital setting. Also, the interventions occurred in individual rather than group settings. Also, the control 
intervention used was a verbal discussion about anxiety management rather than the travel group since it was an individual session.

Since it was the effects of single sessions being considered and there was an anticipated shortage of appropriate participants, one of the participants was asked and agreed to engage in the research twice and thus participant 4 and 6 are the results for the same individual who engaged in two separate sets of data collection.

Based upon these considerations, it was decided to carry out some further analysis to study the effects of these limitations on the results obtained. 


\subsubsection{Results with Exclusion of Participant Measured Twice}

Table 8: Treatment Effect Calculations without One Score for the Client Measured Twice

\begin{tabular}{|c|c|}
\hline Number Of Values & 8 \\
\hline Minimum & -18 \\
\hline $25 \%$ Percentile & -16.50 \\
\hline Median & -13.00 \\
\hline $75 \%$ Percentile & -4.00 \\
\hline Maximum & 1.00 \\
\hline Mean & -10.38 \\
\hline Standard Deviation & 7.07 \\
\hline Standard Error & 2.50 \\
\hline Lower $95 \%$ CI of Mean & -16.29 \\
\hline Upper $95 \%$ CI of Mean & -4.64 \\
\hline \multicolumn{2}{|c|}{ D'Agostino and Pearson's Normality Test } \\
\hline $\mathrm{K} 2$ & 1.56 \\
\hline $\mathrm{p}$ value & 0.46 \\
\hline Passed Normality Test (alpha $=0.05) ?$ & Yes \\
\hline $\mathrm{P}$ value summary & Ns \\
\hline \multicolumn{2}{|c|}{ One Sample t-test } \\
\hline Theoretical mean & 0.00 \\
\hline Actual Mean & -10.38 \\
\hline Discrepancy & 10.38 \\
\hline $95 \%$ CI of discrepancy & -16.29 to -4.64 \\
\hline $\mathrm{t}, \mathrm{df}$ & $\mathrm{t}=4.15, \mathrm{df}=7$ \\
\hline $\mathrm{p}$ value (two tailed) & 0.0043 \\
\hline Significant (alpha=0.05)? & Yes \\
\hline
\end{tabular}

Table 8 and figure 6 identify the results with the exclusion of the result for participant 6 , which is the same participant as participant 4. The sample size now consists of 8 participants. Overall there still remained a significant reduction in anxiety after the music therapy sessions compared to the change in the control sessions $(t(7)=4.15$, $\mathrm{p}=0.0043)$. 
Figure 6: Difference In Changes In Scores Between Pre-Control And Pre-Music Therapy With the Exclusion of One Score for the Participant Measured Twice

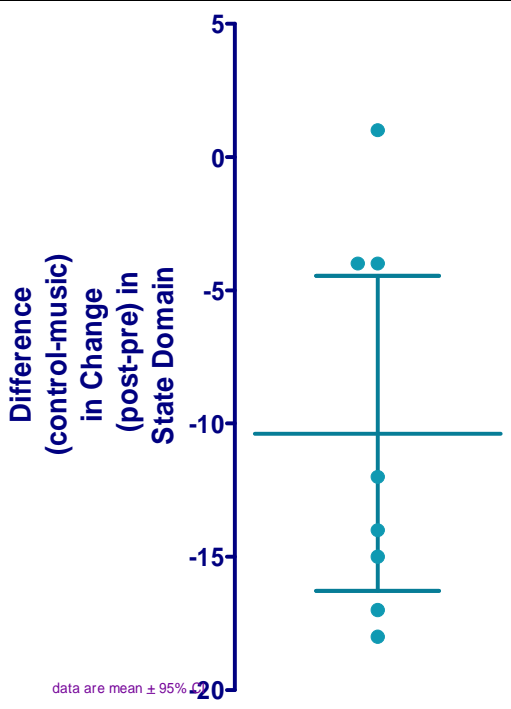




\subsubsection{Results Compared for Different Settings}

Table 9: Comparing Interventions In Different Settings

\begin{tabular}{|c|c|c|}
\hline & Rest home-Individual & Hospital-Group \\
\hline Number Of Values & 3 & 5 \\
\hline Minimum & -18.00 & -15.00 \\
\hline $25 \%$ Percentile & & -14.50 \\
\hline Median & -17.00 & -4.00 \\
\hline $75 \%$ Percentile & & -1.50 \\
\hline Maximum & -12.00 & 1.00 \\
\hline Mean & -15.67 & -7.20 \\
\hline Standard Deviation & 3.22 & 6.98 \\
\hline Standard Error & 1.86 & 3.12 \\
\hline $\begin{array}{l}\text { Lower } 95 \% \text { CI of } \\
\text { Mean }\end{array}$ & -23.65 & -15.87 \\
\hline $\begin{array}{l}\text { Upper } 95 \% \text { CI of } \\
\text { Mean }\end{array}$ & -7.68 & 1.47 \\
\hline \multicolumn{3}{|c|}{ D'Agostino and Pearson's Normality Test } \\
\hline K2 & $\mathrm{N}$ too small & $\mathrm{N}$ too small \\
\hline \multicolumn{3}{|l|}{$p$ value } \\
\hline \multicolumn{3}{|l|}{$\begin{array}{l}\text { Passed Normality Test } \\
(\text { alpha }=0.05) ?\end{array}$} \\
\hline \multicolumn{3}{|l|}{$\mathrm{P}$ value summary } \\
\hline \multicolumn{3}{|c|}{ One Sample t-test } \\
\hline Theoretical mean & 0.00 & 0.00 \\
\hline Actual Mean & -15.67 & -7.20 \\
\hline Discrepancy & 15.67 & 7.20 \\
\hline $95 \%$ CI of discrepancy & -23.65 to -7.68 & -15.87 to 1.47 \\
\hline $\mathrm{t}, \mathrm{df}$ & $\mathrm{t}=8.44, \mathrm{df}=2$ & $\mathrm{t}=2.31, \mathrm{df}=4$ \\
\hline $\mathrm{p}$ value (two tailed) & 0.0137 & 0.0823 \\
\hline $\begin{array}{l}\text { Significant } \\
(\text { alpha=0.05)? }\end{array}$ & Yes & No \\
\hline
\end{tabular}

Table 9 stratifies the results into the two groups of the rest home setting and the hospital setting. The resultant individual sample sizes were too small to test for normality. However, carrying out a one sample t-test indicated that the rest home setting had significantly reduced anxiety [ $\mathrm{t}(2)=8.44, \mathrm{p}=0.0137]$ while the hospital setting failed to reach conventional statistical significance $[\mathrm{t}(4)=2.31, \mathrm{p}=0.0823]$. The statistician identified that the small number of participants in each sample group could be considered to be insufficient for a conclusive answer. 
Table 10: Comparative Analysis of the Rest Home (Individual) And Hospital (Group) Settings

\begin{tabular}{|l|l|}
\hline \multicolumn{2}{|c|}{ Unpaired $t$-test } \\
\hline$p$ value & 0.1012 \\
\hline$p$ value summary & Ns \\
\hline Are means signif. different (alpha=0.05)? & No \\
\hline One or two-tailed p value? & Two-tailed \\
\hline$t$, df & $t=1.94, d f=6$ \\
\hline
\end{tabular}

Table 10 and figure 7 compares the average change in anxiety levels between music therapy and the control intervention for the participants in the rest home and hospital settings. The results indicate that the difference is not statistically significant $t(6)=1.94$, $\mathrm{p}=0.1012$. This means that there is no significant difference between the changes in anxiety for the two settings.

Figure 7: Comparing the Hospital to Rest Home Settings

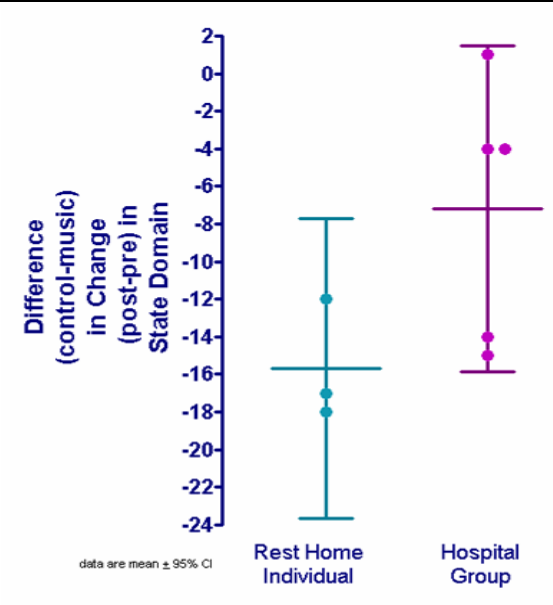

\subsubsection{Variations in Research Personnel}

Table 11: Variations in Research Personnel

\begin{tabular}{|c|c|c|c|c|}
\hline & \multicolumn{2}{|c|}{ Music Therapy } & \multicolumn{2}{c|}{ Control Intervention } \\
\hline Participant & Intervention & Measurement & Intervention & Measurement \\
\hline 1 & MTS \& OT 1 & OT 1 & OT 1 & OT 1 \\
\hline 2 & MTS \& OT 1 & OT 1 & MTS \& OT 1 & OT 1 \\
\hline 3 & MTS \& OT 1 & OT 1 & OT 1 & OT 1 \\
\hline 4 & MTS \& OT 2 & OT 2 & MTS \& OT 2 & OT 2 \\
\hline 5 & MTS \& OT 2 & OT 2 & MTS \& OT 3 & OT 3 \\
\hline 6 & MTS \& OT 3 & OT 3 & MTS \& OT 3 & OT 3 \\
\hline 7 & MTS & OT 2 & OT 2 & OT 2 \\
\hline 8 & MTS \& OT 3 & OT 3 & MTS \& OT 3 & OT 3 \\
\hline 9 & MTS \& OT 3 & OT 3 & MTS \& OT 3 & OT 3 \\
\hline
\end{tabular}

Notes for Table 3: MTS - Music Therapy Student; OT - Occupational Therapy Staff

The research was carried out with the voluntary assistance of the occupational therapy team within the service. Given other professional responsibilities and high turn over of 
staff, there were in total three different occupational therapist who assisted with the research project. The details of this variation in personnel are listed in table 11. The following points can be noted from table 11 .

- All music therapy interventions included the student music therapist.

- All control group interventions included an occupational therapist.

- For participant 1, 3 and 8 due to practical considerations, only the occupational therapy staff member carried out the intervention.

- For participant 7 , due to practical considerations, only the student music therapist carried out the music therapy condition.

- All administration of the measurement tool was carried out by the occupational therapy staff without the presence of the student music therapist in the room.

It was decided that since all the interventions were carried out by professionals from within the same department, the variation between the styles of carrying out and supporting the interventions and measurement would all be to the same professional standard and that therefore the effect of this variable could be considered to be minimal.

Table 4 lists the order in which the interventions were administered for each participant. It indicates that for all the participants except participant 3, the music therapy intervention was administered before the control intervention. It was unclear how long the participants would stay in the ward. Therefore the first intervention administered was the music therapy intervention and if this was successfully administered then it was followed by the control intervention.

\section{Discussion}

This project is a quantitative study and thus this section compares it to the CONSORT statement for reporting randomised control trials which is the gold standard that identifies the features of a randomised control trial (Moher et al., 2001). This section also explores practical difficulties and offers suggestions on how future studies could overcome these difficulties. It offers an exploration of the reasons why music therapy might help reduce anxiety and corresponding considerations for the design of music 
therapy sessions. It concludes with a description of the possible components of a future study of a similar nature, recommended by this researcher.

\subsection{Interpretation of the Results}

All the participants were older persons (over 65 years of age) with a diagnosis of psychiatric disorders. Therefore, the results indicate a positive outlook for the use of music therapy to help reduce anxiety in older persons with psychiatric disorders. However, these results are restricted to represent only the clients who were cognitively able to answer the STAI and therefore this restricts the generalisation of the results for this client group. The deviations from the proposed research design due to practical recruitment challenges inevitably had the effect of weakening the results.

\subsection{Participant Recruitment}

As listed in section 4.1.1 the total population was the patients in the acute inpatient ward during the data collection phase. The exclusion criterion was patients identified by the clinical staff as inappropriate based on clinical grounds and for whom it was felt cognitive difficulties would create challenges in understanding and answering the "State Trait Anxiety Inventory (STAI)."

The acute unit had a provision for 15 patients. Since the patients were acutely unwell, they were often not mentally or physically fit to attend group activities. Therefore, on average, there were 4 patients attending the music therapy group each week. From these patients attending the group, there was on average one client every three sessions that would present as cognitively able to answer the STAI. These potential participants were approached to participate in the research. However, some of these clients declined to participate in this research. Therefore, given the above list of practical exclusions, there was a small sample population realistically available within the acute setting.

Due to time restrictions of the project being part of an educational course, it was decided to expand the sample population to include patients from the community as well. These were patients who were provided a service by the "Mental Health for Older Persons" team. The result, as listed in table seven, indicates that three of the nine participants were recruited from the community. 
The results indicated that participants from the rest home setting had significant reduction in anxiety, though the sample sizes were too small to validate these results. Indicating significant results in both the settings though, would help reinforce that music therapy could be effective in individual as well as group settings, with group settings being presented as a more economical modality of treatment for current hospital settings.

It was considered that since the study measured the change in the anxiety pre- and posta session, it would be permissible to carry out the research on the same client more than once. It was felt that even if the client was already exposed to music therapy, it was the relative change for each session that was of relevance to this project. Consequently, table 7 identified that participant 4 and 6 is the same participant who had the test sequence administered twice. Exclusion of the second set of results for the participant measured twice, still resulted in achieving statistical significance.

\subsection{Measurement Tool}

One of the major limitations in recruiting participants was the cognitive ability of the participants to answer the STAI. It was observed during initial trial runs before the data collection phase that cognitively impaired clients tended to get confused and had difficulty comprehending the STAI. However, at that stage of the study it was felt that there would still be the possibility of obtaining a sufficient number of clients who would be capable of answering the STAI. Also, there were no other obvious standardised tools and it was felt by the researcher and supervisor to be worth the risk. However, as the data-gathering phase progressed, it was realised that the cognitive ability required to answer the STAI presented as a major hurdle towards obtaining a sufficient number of participants. Also, it caused the results to be representative of only a portion of the clients on the ward who could benefit from music therapy. There were a number of nonverbal, cognitively impaired clients for whom anecdotally it was observed music therapy had an impact on anxiety reduction however, this perceived reduction in anxiety could not be quantified due to the limitation of the research tool requiring cognitive ability.

Research by Kvaal et al (2005) described in section 2.4.6 identified the state part of the STAI as a useful case-finding instrument for mental disorders in geriatric patients. 
However, the study was limited to non-demented geriatric inpatients in a stable clinical condition. Having carried out this present study using the STAI with geriatric patients with mental disorders, it is felt that presenting this tool as effective along with the limitations of non-demented and stable critical conditions is misleading. It is felt that the majority of this client group would be in reasonably advanced states of dementia and in critical conditions and excluding this proportion of the population would result in the study not being representative of the majority of this client group.

The issue of the cognitive level of this client group is also highlighted in the study by Ashida (2000) who studied the effects of reminiscence music therapy sessions on changes in depressive symptoms in elderly persons with dementia. This study mentions that it is difficult accurately to diagnose depression in elderly persons with dementia because of their impaired ability to express their moods and inner feelings. Charles Spielberger, the author of the State Trait Anxiety Inventory, was also contacted to obtain his feedback on the use of the scale with this client base, given the practical problems that this study faced. He commented that a possibility would be the use of the State-Trait Anxiety Inventory for Children (STAIC), which would be considerably easier to respond to by persons with lower levels of functional intellectual ability (See Appendix I).

Further discussions with the psychologist in the team, after the data collection phase, resulted in identifying more anxiety scales that are designed for use specifically with the elderly. Table 12 lists these scales. Some of these scales have the benefit of being shorter in length and may therefore be easier to administer. However, all these scales require the clients to identify how they are feeling and therefore would still result in the exclusion of the same patients as the STAI. Thus self-report scales in general may be useful as representative of the general mood of the patient, however it is felt that for research purposes there would need to be an accurate tool that can be reliably administered to have validity of the results.

Table 12: Anxiety Measurement Scales for Older Persons

\begin{tabular}{|l|l|}
\hline \multicolumn{1}{|c|}{ Scale } & \multicolumn{1}{c|}{ Description } \\
\hline $\begin{array}{l}\text { Beck Anxiety Inventory } \\
\text { (Beck \& Steer, 1990) }\end{array}$ & $\begin{array}{l}\text { 21 question likert self-report inventory about how the } \\
\text { person is feeling during the past week }\end{array}$ \\
\hline $\begin{array}{l}\text { Geriatric Anxiety Inventory } \\
\text { (Pachana et al., 2006) }\end{array}$ & $\begin{array}{l}\text { 20 item self-report or nurse-administered scale that } \\
\text { measures dimensional anxiety in elderly people }\end{array}$ \\
\hline
\end{tabular}




\begin{tabular}{|l|l|}
\hline $\begin{array}{l}\text { The Hospital Anxiety and } \\
\text { Depression Scale } \\
\text { (Zigmond \& Snaith, 1983) }\end{array}$ & $\begin{array}{l}\text { A } 14 \text { item scale that provides a brief state measure of } \\
\text { both anxiety and depression }\end{array}$ \\
\hline $\begin{array}{l}\text { Short Anxiety Screening } \\
\text { Test } \\
\text { (Sinoff et al., 1999) }\end{array}$ & $\begin{array}{l}\text { A } 10 \text { item self report anxiety screening test that detects } \\
\text { anxiety disorders in the elderly, even in the presence of } \\
\text { depression }\end{array}$ \\
\hline
\end{tabular}

A visual representational scale may present as feasible option since the clients may be able to comprehend visual images even though they may have difficulties with verbally expressing how they feel. A simple measurement tool, that has been used with other populations presents as possible solution. This is the Visual Analog mood scale (VAS) (Robb, 2000). This scale is represented in figure 8. The VAS consists of a horizontal $100 \mathrm{~mm}$ line which subjects mark to indicate their current level of anxiety. The left anchor of the scale is identified as "zero anxiety" and the right anchor is identified as "maximum anxiety." The distance from the left anchor to the mark made by the subjects can be measured in millimetres and the post- to pre- test difference can be used to identify change in anxiety. This presents as a simple visual tool that may be accessible by more clients. A further modification of this tool could be the use of visual face representations along the scale to help clients better understand and indicate how they feel.

Figure 8: Visual Analog Mood Scale Example

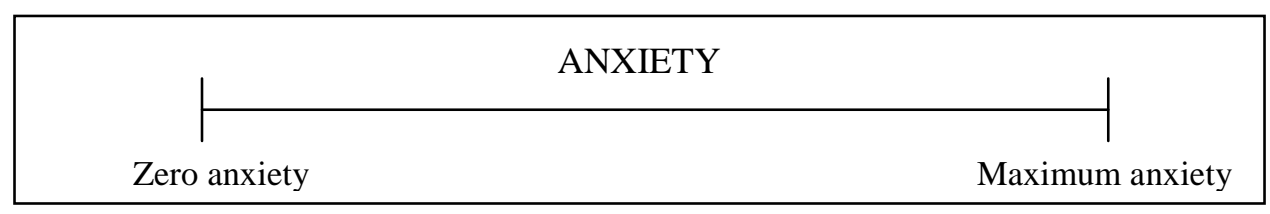

Krout (2001) used a modified version of the VAS as an observational tool for measuring relaxation in the study of effects of single session music therapy interventions on self-reported levels of pain control, physical comfort and relaxation of hospice patients. Similar to the VAS, the author's observational form consisted of a $100 \mathrm{~mm}$ line that connected polar opposites to describe the problem area for relaxation. The two limits were the left anchor for "complete evidenced relaxation" and the right anchor of "complete evidenced tension." However, to aid the observer, under the line the researcher listed behavioural observations as a guide for the observer to determine where on the scale each client lies. The behavioural observations from left to right were calm/states no tension; some observed muscle tension; grimacing; clenching hand/arm; flinching/withdrawing; body contortion/fetal; statements of worst tension. This means 
of an observational scale presents as a possible method of measuring the anxiety for older persons with psychiatric disorders, however the presence of a standardised, reliable observational tool to measure anxiety or it's related areas of relaxation appears to be absent within the literature.

The issue of utilising well documented scales is highlighted in the Cochrane review for music therapy for people with dementia (Vink et al., 2003). It notes that the methodological quality of the existing studies assessing the effects of music therapy is generally poor and identified that more rigorous studies are needed to establish whether music therapy may play a role in the treatment of older people with dementia. One of the recommendations for future trials was the use of reliable and validated outcome measures. Clearly there is a need for researchers to develop and validate appropriate tools for evaluating interventions with this section of the population.

In section 2.4.5 it was identified that the measurement of anxiety can be carried out via measuring subjective or physiological responses of the participants (Knight \& Rickard, 2001). After experiencing a period of facilitating music therapy with this client group, this author would agree that physiological responses would not provide an accurate measure of anxiety in a hospital setting due to the numerous medications being taken by the patients.

Anxiety presents as a state of mind and only the individual themselves can identify accurately their level of anxiety. Therefore, it is felt that the measurement of anxiety for cognitively impaired clients will always be difficult. An alternative means of measurement of physical observable changes such as the individual's state of relaxation may be a more appropriate and valid measure for this client group.

\subsection{Testing Conditions}

The use of clients from the community resulted in variation of testing conditions. 3 of the 9 clients were administered music therapy in rest homes in individual settings. Carrying out the music therapy at the rest home in individual settings would have added confounding variables (for example, the absence of group dynamics within the individual settings). These confounding variables could have affected the resultant change in anxiety. However, it can be noted that music therapy in both settings were carried out by the same student music therapist, which should result in consistency of 
the delivery style of the music therapy intervention. However, the control participants had a variety of facilitators that could have affected these results.

\subsection{Randomisation}

As mentioned, the use of randomisation was not implemented in this project due to the practical restrictions of client recruitment. Clients were in the unit for a relatively short period of time. Randomisation provided a level of complexity that potentially further reduced recruitment. For future projects, with a longer time frame, the advice of the statistician about the method of randomisation could be implemented. This method of randomisation is listed below.

Each of the patients who meet the eligibility criteria (informed consent provided, etc.) would be randomised (sealed envelopes allocating consecutive patients to groups by high or low random numbers (Microsoft Excel) in sorted random number list) to either having STAI followed by music therapy, followed by STAI in one week and STAI followed by the control group, followed by STAI in the subsequent week OR STAI followed by the control group, followed by STAI in one week and STAI followed by music therapy, followed by STAI in a subsequent week.

\subsection{Blinding assessors}

Given the limited resources of a student project, the occupational therapy staff that aided with running the interventions also carried out the assessments. Incorporating blind assessment into the study would have required the presence of another staff member, which would have not been practically feasible. Therefore, blinding of the assessors to minimise assessment bias could not be carried out. This could have created an assessment bias of the occupational therapy staff wanting the occupational therapy model travel group to present more effective results than music therapy. It is assumed that the staff acted as professionals adhering to their professional code of ethics and thus administered the STAI in a non-biased fashion. In addition, this client group often requires the person administering the test to engage in conversation with them to elicit their responses to the STAI. This may have required conversations about the session the client is due to or has just completed attending. Thus practically, blinding the assessors in this setting would be difficult to achieve. 


\subsection{Other Confounding Variables}

Due to the nature of an acute service, the participants could have been on various medications at the time of the music therapy group. Some of these medications may have resulted in a change in the level of anxiety. However, the study was carried out at various times of the day every week and therefore it is felt that the effects of all the patient's results being affected by the medication would be minimal.

\subsection{Appropriateness of the Control Group}

The presence, of a control group has been useful in isolating the effects of the music therapy intervention from other factors such as the effect of the therapists on the clients. The need for a control group was also highlighted in other studies measuring anxiety by Krout (2001) and Choi (2008). Also the Cochrane review for dementia identified the lack of control groups as one of the limitations of music therapy studies (Vink et al., 2003).

The use of a travel group as a verbal therapeutic control group was beneficial in this setting since it was a well established group with pre-existing resources. It aimed to function as a distraction for the clients from their reality of being within the hospital setting. However, there also are specific anxiety management occupational therapy based group models. These may provide a better comparison since they specifically focus on anxiety management.

\subsection{Why might Music Therapy reduce anxiety?}

Interestingly, all the music therapy literature reviewed for this study, failed to indicate the reason for music therapy causing anxiety reduction. The literature tended to present results that indicated that music therapy does reduce anxiety though the process or reason for this phenomenon was not really discussed. The possible reason for this discrepancy is that the area of anxiety and anxiety management is a complex field that would require specialised research to study this co-relation between anxiety reduction and music therapy. The following section aims to provide a personal understanding of the phenomenon and offer a personal view on the subject. It is not intended to be a comprehensive authoritative view on this subject, but rather as a personal explorative musing to understanding this area. 
The first step to exploring this question was to have an in-depth understanding and defining of the terms stress, anxiety and relaxation. These terms are often interchanged in literature though they actually seem to present with unique characteristics that define the role of each of these terms. One definition of stress and anxiety is explained in section 2.4. As this section indicates, firstly, a state of anxiety requires the presence of a stressor. In an ideal world, a hospital environment provides no objective anxiety since there should be no reason for the human "fight or flight" mechanism to be activated. Thus any anxiety caused in this setting can be considered to be neurotic, rather than objective anxiety. The anxiety could be said to be due to repressed past memories being triggered such as the past fear of hospitals, fear of new environments. While these are realistic fears for a person to experience, there is no theoretical reason for this resulting in a high state of anxiety. Section 2.4.1 mentions the stereotypical bodily reactions to a state of anxiety. These reactions seem to be characterised by the body physiologically being in a state of tension. This can be represented as the body being a state opposite to that of a state of relaxation.

The possible means by which music can aid a reduction of anxiety is gleaned from the work by Joseph Wolpe with regard to systematic desensitisation (Wolpe, 1982). These treatments work by pairing a state of physical and mental relaxation with an anxiety arousing object or scene imagined by the patient. The treatment rationale is that a physical state of relaxation is incompatible with the physical state of tension that is experienced when a person is in a state of anxiety. Music therapy is often proven to aid physical relaxation. Therefore, it could be hypothesised that since music therapy aids physical relaxation, it correspondingly creates a physical state that is incompatible with the physical state of tension that is experienced in a state of anxiety. Therefore, it results in a reduction of anxiety.

The possible reason for music aiding physical relaxation is rooted in the entrainment theory. Music could exert it's effect via the entrainment or synchronisation of body rhythms with those of the musical selection (Chlan, 1998). Entrainment is the process whereby two objects vibrating at similar frequencies will tend to interact and come into sync with one another, thereby resonating at the same frequency. The entrainment of body rhythms with relaxing music is thought to decrease sympathetic nervous system activity, resulting in a dampening in the arousibility of the central nervous system. This 
response, in turn, lead to altered states of consciousness and decreased neuromuscular arousal which are manifested as physiological indicators of the relaxation response by decreases in heart rate, respiratory rate, metabolic arte, oxygen consumption, skeletal muscle tension, epinephrine level, gastric acidity and motility, and sweat gland activity with decreased blood pressure in hypersensitive individuals (Chlan, 1998).

Thus it can be concluded that a personal interpretation of the effect of music on anxiety is that music results in physical relaxation, which is incongruent with the state of tension associated with anxiety and thus music therapy results in a reduction of anxiety.

\subsection{Anxiety Considerations for Music therapy Sessions}

This study examines the role of music therapy in reducing anxiety. It provides ideas for how and why music therapy can aid reduce anxiety. However, as part of the reflection on anxiety and music therapy, it was felt that music therapy could also potentially present the opportunity for an increase in anxiety. It is hoped that suitably qualified practicing music therapists would already be aware of the scenarios below and thus have minimised their impact and effectively used music therapy to reduce anxiety. However, to reinforce these ideas, they are offered below. These ideas are a personal view from the researcher based upon the practical experience of working with older persons with psychiatric disorders, rather than being based upon pre-existing literature.

\subsubsection{Attending music therapy for the first time}

Given the nature of an acute setting, clients may only attend one music therapy session. Therefore, when asked to attend music therapy, it may present as their first experience of this form of therapy. From the experience of running this group, it was noticed that the main stressor for this encounter is that the clients feel that they may be expected to sing or play instruments. They often mentioned that they are non-musical or "don't have a musical bone in their body." To minimise the effect of this stressor, it was always mentioned to the patients that there is no need for them to have to sing or play instruments during the session and they could just come along and listen to the music and that it would be permissible to leave at any time. 


\subsubsection{Entering the Music Therapy Room}

The music therapy sessions occurred at the meeting room on the ward. Most of the clients who came for music therapy would have never been in this room before. There could possibly be anxiety in entering a new room and new setting of a music therapy session. To minimise this anxiety for the clients, it is ensured that the room is set up before they arrived to minimise the confusion or disorientation caused by having to move chairs or furniture. At the start they are also verbally welcomed and informed that they can leave at any time they wish to, thus allaying a possible sense of being trapped. The session also started with a welcome song to help musically extend a sense of invitation to the clients

\subsubsection{The Presence of Instruments}

The presence and introduction of instruments during the session could create within the clients the sense of anxiety felt when asked to attend the session about not being able to play musical instruments. However, it is preferred during the music therapy session to have the clients be able to use the instruments to express themselves. To aid the access of the instruments by the clients, the instruments chosen for the session were mainly instruments that could be used for music-making without a great deal of prior knowledge or musical ability. The instruments available were an egg shaker, bongos, rain stick, caxixi, ocean drum, jingle bells and triangle. These instruments can be sounded without the need for musical knowledge or dexterity required to play instruments such as a guitar. These instruments also represent instruments that the clients have usually never seen or encountered before such as the ocean drum. Thus this also helps create a sense of curiosity that aids the client desire to engage in interacting with the instrument. Also, if a client strongly expresses the desire to not wish to play, then this decision is respected. Thus these conditions can help reduce the possible anxiety created by the idea by the client that they cannot play the instrument.

\subsubsection{Unfamiliar Musical Structures}

The styles and ethnic preferences of a client may result in them being unfamiliar with certain musical structures they could encounter during the music therapy session. An example is engaging in an atonal improvisation. This may present as a new experience for the client and may cause a state of anxiety. To help minimise this possible anxiety, the sessions were client focussed and took into account the musical preferences of the 
clients. In addition, when new experiences such as an improvisation were attempted, it was done within a framework that could be familiar to the clients such as the blues format. It was hoped that in these cases, the musical structure would provide a holding function that would help reduce any possible anxiety by the clients.

\subsubsection{Ability of music to evoke memories}

Music can evoke memories for clients. These memories could trigger a state of anxiety. When this did occur, the student music therapist aimed to use music's cathartic effect to hold the evoked responses (Casement, 1990). Thus the ability of music to evoke memories could consciously be used by the therapist and client within the session to help the client recreate and deal with the stressor within the safe therapeutic space of the music therapy session.

\subsubsection{Comparing Music Therapy to the Control Intervention}

For this study, music therapy resulted in greater reduction of anxiety pre- to postsession as compared to the control group. The reasons for this difference are explored in this paragraph. The perception of music as an acceptable, familiar and fun activity as compared to the travel group, which was a new concept to most clients, could be the reason for differences in the reduction of anxiety. Another view is the psychoanalytic concept of the presence of the third in a therapeutic relationship. The third can represent a point of reference outside of the dyad of the therapist and the patient (Benjamin, 2004). Within the music therapy session, the music could be viewed as the third and within the travel group the pictures and words bought into the session could present the third. Given that a person acted as their own control and that both the music therapy and control group were run by the same facilitators, the resultant anxiety change would be due to this described factor of "the third." Assuming that the aim of the session would be to create physical relaxation, the idea would be that music therapy would be more effective due to a better "holding condition" (Casement, 1990). 


\subsection{Recommendations for Future Studies}

\subsubsection{Quantitative Studies}

Based upon the experience gained from this current project, the following is a proposed design for future similar studies. Future studies based on the same principles as the current study would help validate the studies via replication.

\section{Sample Population:}

Patients admitted to the hospital ward for, "Older Persons with Psychiatric Disorders." The exclusion criteria would be only the patients for whom the clinical staff felt that music therapy was inappropriate on clinical grounds.

\section{Sample Size:}

The sample size could still be considered to be 10 , since this current study demonstrates that this sample size has the potential to deliver statistically significant results for a pilot

\section{$\underline{\text { Randomisation: }}$}

Randomisation could be done via the use of sealed envelopes allocating consecutive patients to groups by high or low random numbers (Microsoft Excel) in sorted a random number list.

\section{Interventions:}

The music therapy intervention could continue as per the current format along with considerations for the potential stressors inherent in music therapy sessions. The control group could be an established reliable occupational therapy anxiety management group programme.

\section{Measurement Tool:}

A majority of the clients within this client group present as cognitively impaired. Anxiety presents as a state of mind. Therefore to get an accurate understanding of the state of anxiety of a person, researchers need to enquire of the person him or herself to indicate perceived levels of anxiety. This project has demonstrated that this process is difficult to achieve with a majority of the client group. Physical relaxation has been demonstrated to be a means of achieving anxiety reduction. Physical relaxation is 
potentially observable. Therefore the recommendation would be to use an observational tool to measure the change in physical relaxation of the client. A standardised tool to carry out this measure was not found within the literature. Measures such as heart rate and respiratory rate could be considered as measures of relaxation.

\section{Data Collection Method:}

The data collection could be carried out in a designated observation period pre- and post- the interventions. The clients can continue to function as their own control to reduce the impact of extraneous variables.

\subsubsection{Qualitative studies}

Qualitative studies could be used to reinforce and further explore the area of anxiety and music therapy. Following are some suggested areas of research.

- A study of the subjective perception of the changes in the clients due to music therapy by their carers or hospital staff. This study would help create a list of areas that music therapy is perceived to benefit older persons with psychiatric disorders.

- A study of music therapists' experiences and perceptions of the effect of music therapy on anxiety. This study would help develop an understanding of the reasons for the effects of music therapy on anxiety. 


\section{Conclusions}

In this pilot study, single sessions of music therapy significantly reduced the level of anxiety for older persons with psychiatric disorders [ $\mathrm{t}(8)=4.626, \mathrm{p}<0.0017]$ as compared to the control intervention measured by the state part of the "State Trait Anxiety Inventory". There was no evidence for a significant carryover effect since the baselines prior to each intervention did not differ significantly $(\mathrm{p}=0.55)$. Two possible limitations of these results are as follows: 1) That the outcome represents only a minority of the sample population since the participants were required to be sufficiently cognitively able to answer the "State Trait Anxiety Inventory"; and 2) 3 out of the 9 participants were recruited with a deviation from the standard protocol and one of the clients was sampled twice, due to practical considerations of achieving the sample size within the given time. The study highlights the lack of a suitable measurement tool for evaluating music therapy with a client base of older persons with psychiatric disorders. It also illustrates some of the challenges of conducting appropriate outcome research with this vulnerable population in short-term care, as has been observed in previous music therapy studies in the field. The measurement of observable rather than client reported variables is suggested as a means of sampling a wider range of this population. Physical relaxation, rather than anxiety, is suggested as a measure for future studies. 


\section{References}

Aldridge, D. (Ed.). (2000). Music Therapy in Dementia Care : More New Voices. London: Jessica Kingsley.

Ashida, S. (2000). The effect of reminiscence music therapy sessions on changes in depressive symptoms in elderly persons with dementia. Journal of Music Therapy, 37(3), 170-182.

Ayson, C. (2008). Child-Parent Wellbeing in a Paediatric Ward: The Role of Music Therapy in Supporting Children and Their Parents Facing the Challenge of Hospitalisation. Voices: A World Forum for Music Therapy Retrieved July 31, 2008, from http://www.voices.no/mainissues/mi40008000261.php

Beck, A., \& Steer, R. (1990). Beck Anxiety Inventory Manual. San Antonio: The Psychological Corporation.

Benjamin, J. (2004). Beyond Doer and Done to: An Intersubjective View of Thirdness. Psychoanalytic Quarterly, 73, 5-46.

Biley, F. C. (2000). The effects on patient well-being of music listening as a nursing intervention: a review of the literature. Journal of Clinical Nursing, 9(5), 668677.

Bonny, H. (1983). Music Listening for Intensive Coronary Care Units: A Pilot Project. Music Therapy 3(1), 4-16.

Bright, R. (1991). Music In Geriatric Care: A Second Look. New South Wales, Australia: Music Therapy Enterprises.

Brooks, M., \& O-Rourke, A. (1992). A time for music : the place of music in the care and support of the elderly : report on a music therapy project undertaken for the Wellington Society for Music Therapy. Annual Journal - New Zealand Society for Music Therapy, 7-35.

Bruer, R. A., Spitzriagel, E., \& Cloninger, C. R. (2007). The temporal limits of cognitive change from music therapy in elderly persons with dementia or dementia-like cognitive impairment: A Randomized controlled trial. Journal of Music Therapy, 44(4), 308-328.

Casement, P. (1990). On Learning From the Patient. London: Routledge.

Cevasco, A. (2005). Comparison of Movement-to-Music, Rhythm Activities and Competitive Games on Depression, Stress, Anxiety, and Anger of Females in Substance Abuse Rehabilitation. Journal of Music Therapy, XL11(1), 64-80.

Chlan, L. (1998). Effectiveness of a music therapy intervention on relaxation and anxiety for patients receiving ventilatory assistance. Heart \& Lung, 27(3), 169176.

Choi, A., Lee, M. S., \& Lim, H. (2008). Effects of Group Music Intervention on Depression, Anxiety, and Relationships in Psychiatric Patients: A Pilot Study. The Journal of Alternative and Complementary Medicine, 14(5), 567-570.

Cochrane. (2009). The Cochrane Collaboration. Retrieved 7 July, 2009, from http://www.cochrane.org

CONSORT. (2009). CONSORT Transparent Reporting of Trials. Retrieved 07 July, 2009, from http://www.consort-statement.org

DSMIV. (1995). Diagnostic And Statistical Manual Of Mental Disorders: Fourth Edition (4 ed.). New Delhi: Jaypee Brothers.

Ferrer, A. (2007). The Effect of Live Music on Decreasing Anxiety in Patients Undergoing Chemotherapy Treatment Journal of Music Therapy, 44(7), 242255. 
Gold, C., Heldal, T. O., Dahle, T., \& Wigram, T. (2005). Music therapy for schizophrenia or schizophrenia-like illnesses. Cochrane Database of Systematic Reviews(2).

Goldberger, L., \& Breznitz, S. (Eds.). (1982). Handbook of stress : Theoretical and Clinical Aspects. New York: Free Press.

Graphpad. (2009). GraphPad Software: Prism 5 Users Guide. Retrieved 17 Jan, 2009, from http://www.graphpad.com/Support/support.cfm

Gregory, D. (2000). Test Instruments used by Journal of Music Therapy Authors from 1984-1997. Journal of Music Therapy, 37(2), 79-94.

Hanser, S. B. (1988). Controversy in music listening/stress reduction research. The Arts in Psychotherapy, 15(3), 211-217.

Hanser, S. B., \& Thompson, L. (1994). Effects of a music therapy strategy on depressed older adults. Journal of Gerontology, 49(6), 265-269.

Hepburn, M. (1997). Music therapy with the older person. Annual Journal - New Zealand Society for Music Therapy, 54-61.

Jacoby, R., \& Oppenheimer, C. (2002). Psychiatry in the Elderly (Third ed.). Oxford: Oxford University Press.

Jones, J. (2005). A Comparison of Songwriting and Lyric Analysis Techniques to Evoke Emotional Change in a Single Session with People Who are Chemically Dependent. Journal of Music Therapy, 42(2), 94-100.

Kabacoff, R. I., Segal, D. L., Hersen, M., \& Van Hasselt, V. B. (1997). Psychometric properties and diagnostic utility of the Beck Anxiety Inventory and the state-trait anxiety inventory with older adult psychiatric outpatients. Journal of Anxiety Disorders, 11(1), 33-47.

Knight, W., \& Rickard, N. (2001). Relaxing Music Prevents Stress-Induced Increases in Subjective Anxiety, Systolic Blood Pressure, and Heart Rate in Healthy Males and Females Journal of Music Therapy, 38(4), 254-272.

Krout, R. (2001). The effects of single-session music therapy interventions on the observed and self-reported levels of pain control, physical comfort, and relaxation of hospice patients. American Journal of Hospice \& Palliative Care, 18(6), 383-390.

Krout, R. (2005). Applications of Music Therapist-Composed Songs in Creating Participant Connections and Facilitating Goals and Rituals During One-Time Bereavement Support Groups and Programs. Music Therapy Perspectives, 23(2), 118-128.

Kvaal, K., Ingun, U., Nordhus, H., \& Engedal, K. (2005). The Spielberger State-Trait Anxiety Inventory (STAI): the state scale in detecting mental disorders in geriatric patients. International Journal of Geriatric Psychiatry, 20(7), 629-634.

MOH. (2002). Health of Older Persons Strategy. Wellington: Ministry of Health.

MOH. (2004). A Portrait of Health: Key results of the 2002/03 New Zealand Health Survey. Wellington: Ministry of Health.

Moher, D., Schulz, K. F., \& Altman, D. G. (2001). The CONSORT statement: revised recommendations for improving the quality of reports of parallel-group randomised trials. . Lancet, 357(9263), 1191-1194.

Molyneux, C. (2005). Music therapy as a short-term intervention with individuals and families in a child and adolescent mental health service. British journal of music therapy, 19(2), 59.

Odell-Miller, H. (1995). Approaches to music therapy in psychiatry with specific emphasis upon a research project with the elderly mentally ill. In T. Wigram, B. 
Saperston \& R. West (Eds.), The Art and Science of Music Therapy: A

Handbook (pp. 83-111). United Kingdom: Harwood academic.

Odell-Miller, H. (2005). Why Provide Music Therapy in the Community for Adults

With Mental Health Problems? Voices: A World Forum for Music Therapy

Retrieved March 18, 2008, from

http://www.voices.no/mainissues/mi40005000172.html

Pachana, N., Bryne, G., Siddle, H., Koloski, N., Harley, E., \& Arnold, E. (2006).

Development and validation of the Geriatric Anxiety Inventory. International

Psychogeriatrics, 19(1), 103-114.

Perkins, C. (2004). The NZ dementia guide. Auckland: Random House.

Raijmaekers, J. (1993). Music Therapy's Role in the Diagnosis of Psycho-Geriatric

Patients in the Hague. In M. Heal \& T. Wigram (Eds.), Music Therapy in Health and Education. London: Jessica Kingsley.

Rickson, D. (1998). The use of music and music therapy in the care of older people. Annual Journal - New Zealand Society for Music Therapy, 15-26.

Rickson, D. (2006). Reflections On The Nature of Relationships In Brief Music Therapy Encounters With Children Who Have Development Difficulties. New Zealand Journal of Music Therapy, 4, 23-45.

Robb, S. (2000). Music Assisted Progressive Muscle Relaxation, Progressive Muscle Relaxation, Music Listening, and Silence: A Comparison of Relaxation Techniques Journal of Music Therapy, 37(1), 2-21.

Sherratt, K., Thornton, A., \& Hatton, C. (2004). Music interventions for people with dementia: a review of the literature. Aging \& Mental Health, 8(1), 3-12.

Silverman. (2003). The influence of music on the symptoms of psychosis: A metaanalysis. Journal of Music Therapy, 40(1), 27-40.

Silverman, M. J., \& Marcionetti, M. J. (2004). Immediate effects of a single music therapy intervention with persons who are severely mentally ill. The Arts in Psychotherapy, 31(5), 291-301.

Sinoff, G., Ore, L., Zlotogorsky, D., \& Tamir, A. (1999). Short Anxiety Screening Test - A Brief Instrument For Detecting Anxiety In The Elderly. International Journal of Geriatric Psychiatry, 14, 1062-1071.

Spielberger, C. D. (1979). Understanding Stress and Anxiety. London: Harper and Row. Spielberger, C. D. (2008). Query about the use of STAI for a research project. Florida. Spielberger, C. D., Gorsuch, R. L., Lushene, R., Vagg, P. R., \& Jacobs, G. A. (1983). Manual for the State-Trait Anxiety Inventory. Palo Alto, CA: Consulting Psychologists Press.

StatisticsNZ. (2007). New Zealand's 65+ Population: A statistical volume. Wellington: Statistics New Zealand.

Suzuki, A. (1998). The Effects of Music Therapy on Mood and Congruent Memory of Elderly Adults with Depressive Symptoms. Music Therapy Perspectives, 16, 7580.

Vink, A., Birks, J., Bruinsma, M., \& Scholten, R. (2003). Music therapy for people with dementia. Cochrane Database of Systematic Reviews(4).

Walworth, D. (2003). The Effect of Preferred Music Genre Selection Versus Preferred Song Selection on Experimentally Induced Anxiety Levels. Journal of Music Therapy, XL(1), 2-14.

Webster, J. (1994). Moving into an institution : music therapy to support the elderly in their loss and grief. Annual Journal - New Zealand Society for Music Therapy, 7-34. 
Whipple, J. (2003). Surgery Buddies: A Music Therapy Program for Pediatric Surgical Patients. Music Therapy Perspectives, 21, 77-83.

Whitehead-Pleaux, A., Baryza, M., \& Sheridan, R. (2006). The Effects of Music Therapy on Pediatric Patients' Pain and Anxiety During Donor Site Dressing Change. Journal of Music Therapy, XLIII(2), 136-153.

Wigram, T., Pederson, I., \& Bonde, L. (2004). A Comprehensive Guide to Music Therapy. London: Jessica Kingsley Publishers.

Wikipedia. (2008). Cronbach's Alpha. Retrieved 17 Jan, 2009, from http://en.wikipedia.org/w/index.php?title=Cronbach\%27s_alpha\&oldid=257221 $\underline{362}$

Wikipedia. (2009). Validity (Statistics). Retrieved 17 Jan, 2009, from http://en.wikipedia.org/w/index.php?title=Validity_(statistics)\&oldid=26120687 $\underline{0}$

Wolpe, J. (1982). The Practice of Behaviour Therapy (Third ed.). New York: Pergamon Press.

Wong, H., Lopez-Nahas, V., \& Molassiotis, A. (2001). Effects of music therapy on anxiety in ventilator-dependent patients. Heart \& Lung, 30(5), 376-387.

Zigmond, A. S., \& Snaith, R. P. (1983). The Hospital and Depression Scale. Acta Psychiatrica Scandinavica, 67, 361-370. 


\section{Appendices}

Appendix A: Personal Communication with Charles Spielberger re. the suitability of the State Trait Anxiety Inventory for Older Persons with Psychiatric Disorders.

Appendix B: Summary Sheet for Potential Research Participants

Appendix C: Information Sheet for Potential Research Participants

Appendix D: Consent Form for Potential Research Participants

Appendix E: Statistician's Report for the Proposed Method of Analysis

Appendix F: State Part of the State Trait Anxiety Inventory

Appendix G: Project Approval from the Northern X Regional Ethics Committee, New Zealand

Appendix H: Project approval by the Academic Committee of the New Zealand School of Music

Appendix I: Personal Communication with Charles Spielberger re. the suitability of the State Trait Anxiety Inventory for Older Persons with Psychiatric Disorders, following the carrying out the data collection phase 


\title{
Appendix A: Personal Communication with Charles Spielberger re. the suitability of the State Trait Anxiety Inventory for Older Persons with Psychiatric Disorders.
}

\author{
Print \\ From: Spielberger, Charles (spielber@ cas.usf.edu) \\ To: Ajay Castelino \\ Date: Saturday, 7 June, 2008 7:38:05 AM \\ Subject: RE: Query about the use of STAI for a research project
}

Page 1 of 2

\author{
Ajay Castelino, MA in Music Therapy \\ New Zealand School of Music \\ Dear Mr. Castelino:
}

I was pleased to learn of your interest in using our State-Trait Anxiety Inventory (STAI) in your thesis research on the effects of music therapy on anxiety in older persons with psychiatric disorders, and appreciate your sending me a summary of your pilot study. Based on the information that you provided, I believe the STAI would, indeed, be an appropriate measure for assessing change in state anxiety before and after your intervention.

In addition to obtaining pre- and post- measures of S-Anxiety, I recommend that you also administer the STAI T-Anxiety scale in your study. This would permit you to evaluate the differential effects of music therapy on S-Anxiety for patients who are high or low in T-Anxiety. If you have any questions about the STAI, please don't hesitate to bring them to my attention.

If you decide to use the STAI in your thesis research, please fill out the attached Request Form, which must also be signed by your faculty advisor. Permission to reproduce and use this copyrighted measure in your research without charge requires your agreement to share your research findings with us when these are available.

I sincerely hope the STAI will prove useful in your research. Very best wishes.

Charles D. Spielberger, PhD, ABPP, Distinguished Research Professor of Psychology

Director, Center for Research in Behavioral Medicine and Health Psychology,

PCD 4118G University of South Florida, 4202 East Fowler Avenue, Tampa, FL 33620-7200

Phone (813) 974-2342; Fax (813) 974-4617; Email: spielber@ cas.usf.edu

-----Original Message-----

From: Ajay Castelino [mailto:ajaycastelino@yahoo.co.nz]

Sent: Wednesday, June 04, 2008 6:13 PM

To: Spielberger, Charles

Cc: Sarah Hoskyns

Subject: Query about the use of STAI for a research project

Hello Mr Spielberger

I obtained your email address through www.mindgarden.com. I'm currently studying for a 'Masters in Music Therapy' through the 'New Zealand School of Music.' As part of my course requirements, I'm doing a research project for which I wanted to use the State Strait Anxiety Inventory. Below is a summary of the research design.

Would you be able to advise me if the STAI is an appropriate tool to use for this study? In particular, is 
Appendix B: Summary Sheet for Potential Research Participants

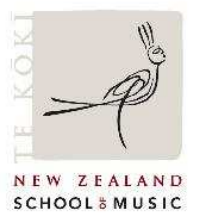

\section{SUMMARY SHEET FOR PARTICIPANTS IN A RESEARCH PROJECT INVESTIGATING THE EFFECTS OF MUSIC THERAPY ON LEVELS OF ANXIETY}

- This is an invitation to participate in a research project that studies the effect of single sessions of music therapy on the level of anxiety.

- It involves attending one 40 minute session of music therapy and one 40 minute session of reminiscence therapy. We will compare if either of these help you with anxiety.

- Music therapy is the use of music to help people express themselves through listening, singing or playing music.

- Reminiscence therapy is the use of material objects to aid recall memories of past events.

- There also is a questionnaire to be filled 4 times. The questionnaire takes about 10 minutes to complete and consists of questions about how you are feeling at the present moment.

- If you wish to participate, we will provide you with an information sheet with more details and a consent form to sign.

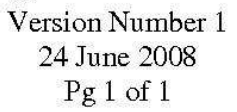


Appendix C: Information Sheet for Potential Research Participants

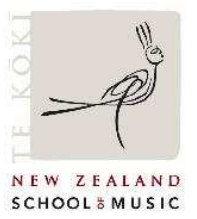

INFORMATION SHEET FOR PARTICIPANTS IN A RESEARCH PROJECT INVESTIGATING THE EFFECTS OF MUSIC THERAPY ON LEVELS OF ANXIETY

\begin{tabular}{|l|l|}
\hline Principal Investigator & Supervisor \\
Ajay Castelino & Sarah Hoskyns \\
Masters of Music Therapy Student & Associate Professor, \\
New Zealand School of Music & Director of Master of Music \\
& Therapy Programme \\
& NZSM, PO Box 2332, Wellington \\
& Phone: (04) 8015799 x 6410 \\
& Email: sarah.hoskyns@nzsm.ac.nz \\
\hline
\end{tabular}

\section{About Myself and the Research}

You are invited to take part in research to study if single sessions of music therapy can help reduce anxiety levels. I'm Ajay and am currently studying towards a 'Masters in Music Therapy' through the 'New Zealand School of Music.' As part of my training, I've been practicing as a music therapist at this ward since February 2008. I'm also going to be carrying out the research. After receipt of this information sheet, you will have at least two days to consider if you wish to participate before having to make a decision. You have the right to decline and you will still be able to attend music therapy and continue to have full access to all the services you are currently being offered at the hospital.

\section{What the Study Involves}

- The study involves you having to fill in a questionnaire 4 times. The questionnaire consists of 20 questions about how you are feeling at the given moment. You have to rate your answers on a scale of 1 to 4 . The questionnaire takes about 10 minutes to complete.

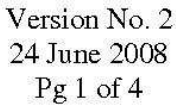


- This questionnaire will need to be filled before and after a 40 minute music therapy session. Music therapy is the use of music to help people express themselves through listening, singing or playing music. There is no requirement for you to be able to sing or play any instrument to participate in music therapy.

- The questionnaire will also have to be filled before and after a 40 minute reminiscence therapy session. Reminiscence therapy is the use of material objects to aid evoke associations and memories of past events.

- The information will be studied to analyse if music therapy helps reduce anxiety levels as compared to reminiscence therapy.

- After the study is concluded, the questionnaire will be stored in a locked secure place at the New Zealand School of Music for 10 years and then destroyed.

- There will be a total of 10 participants in the study and the overall research will last for 4 months.

- The benefit of participating in the study is that you will have the experience of music therapy and have the opportunity to assess for yourself if this intervention will be of benefit to you.

- If you do agree to take part you are free to withdraw from the study at any time, without having to give a reason and this will in no way affect your continuing health care. Participation in this study will be stopped should any harmful effects appear or if the doctor feels it is not in your best interests to continue.

\section{General}

More information can be obtained about the study by talking to me or the occupational therapists at the ward. If you require an interpreter during the research, it can be provided through the interpreter services at Middlemore Hospital. You may also have a friend, family or whanau support to help you understand the 
risks and/or benefits of this study and any other explanation you may require.

If you have any questions or concerns about your rights as a participant in this research study you can contact an independent health and disability advocate. This is a free service provided under the Health and Disability Commissioner Act.

Telephone: (NZ wide) 0800555050.

Free Fax (NZ wide): 080027877678 (0800 2 SUPPORT)

Email (NZ wide): advocacy@hdc.org.nz

\section{Results}

As the research is part of a Masters thesis, it may take some time for all the research to be written up. A copy of the completed research results will be provided to the office at the ward for 'Older Persons with Psychiatric Disorders' at Middlemore Hospital.

Please feel free to contact me or my supervisor (contact details at the beginning) if you have any questions about this study.

\section{Statement of Ethical Approval}

This study has received ethical approval from the Northern X Regional Ethics Committee.

\section{Compensation}

In the unlikely event of a physical injury as a result of your participation in this study, you may be covered by ACC under the Injury Prevention, Rehabilitation and Compensation Act. ACC cover is not automatic and your case will need to be assessed by ACC according to the provisions of the 2002 Injury Prevention Rehabilitation and Compensation Act. If your claim is accepted by ACC, you still might not get any compensation. This depends on a number of factors such as whether you are an earner or non-earner. ACC usually provides only partial 
reimbursement of costs and expenses and there may be no lump sum compensation payable. There is no cover for mental injury unless it is a result of physical injury. If you have ACC cover, generally this will affect your right to sue the investigators.

If you have any questions about $\mathrm{ACC}$, contact your nearest $\mathrm{ACC}$ office or the investigator. 


\section{Appendix D: Consent Form for Potential Research Participants}

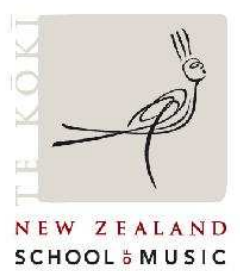

\section{CONSENT FORM}

Title of Research Project: Effect Of Music Therapy On The Level Of Anxiety In Older Persons With Psychiatric Disorders

\section{REQUEST FOR INTERPRETER}

\begin{tabular}{|l|l|c|c|}
\hline English & I wish to have an interpreter. & Yes & No \\
\hline Maori & E hiahia ana ahau ki tetahi kaiwhakamaori/kaiwhaka pakeha korero. & $\mathrm{Ae}$ & Kao \\
\hline $\begin{array}{l}\text { Cook } \\
\text { Island }\end{array}$ & Ka inangaro au i tetai tangata uri reo. & $\mathrm{Ae}$ & Kare \\
\hline Fijian & Au gadreva me dua e vakadewa vosa vei au & Io & Sega \\
\hline Niuean & Fia manako au ke fakaaoga e taha tagata fakahokohoko kupu. & E & Nakai \\
\hline Samoan & Ou te mana'o ia i ai se fa'amatala upu. & Ioe & Leai \\
\hline Tokelaun & $\begin{array}{l}\text { Ko au e fofou ki he tino ke fakaliliu te gagana Peletania ki na gagana } \\
\text { o na motu o te Pahefika }\end{array}$ & Ioe & Leai \\
\hline Tongan & $\begin{array}{l}\text { Oku ou fiema'u ha fakatonulea. } \\
\text { Other languages to be added following consultation with relevant } \\
\text { communities. }\end{array}$ & Io & Ikai \\
\hline
\end{tabular}

I have read and I understand the information sheet dated 24 June 2008 for volunteers taking part in the study designed to measure change in anxiety levels due to music therapy. I have had the opportunity to discuss this study. I am satisfied with the answers I have been given.

$\square$ I have had the opportunity to use whanau support or a friend to help me ask questions and understand the study.

$\square$ I understand that taking part in this study is voluntary (my choice) and that I may withdraw from the study at any time and this will in no way affect my continuing health care

$\square$ I have had this project explained to me by a member of staff team

$\square$ I understand that my participation in this study is confidential and that no material which could identify me will be used in any reports on this study.

$\square$ I understand that the treatment, or investigation, will be stopped if it should appear harmful to me.

Version Number 2

24 June 2008

$\mathrm{Pg} 1$ of 1 
$\square$ I understand the compensation provisions for this study.

$\square$ I have had time to consider whether to take part.

$\square$ I know who to contact if I have any side effects to the study.

$\square$ I know who to contact if I have any questions about the study.

Date

Signature

Researcher: Ajay Castelino

Contact Number: 0212606302

Project Explained By

Occupational Therapist / Music Therapy Co-facilitator

Signature

Date

Version Number 2

24 June 2008

$\mathrm{Pg} 2$ of 2 


\title{
Appendix E: Statistician's Report for the Proposed Method of Analysis
}

$\begin{array}{ll}\text { Print } & \text { Page } 1 \text { of } 1\end{array}$

From: Greg Gamble (gd.gamble@auckland.ac.nz)

To: Ajay Castelino

Date: Wednesday, 9 July, 2008 2:02:31 PM

Subject: RE: Stats report request

Hi Ajay,

I understand that your project aims to explore the change (if any) in anxiety levels after a music intervention session in older people with psychiatric disorders. The setting is an inpatient acute hospital.

The instrument chosen is the 'state' domain of the State Trait Anxiety Inventory (STAI). Originally it was proposed that this instrument be administered before and after the intervention music session however given the lack of experience of repeated testing in this patient cohort a cross-over design with subjects randomized to either music intervention first or just usual observation was suggested as a way of demonstrating that changes over time (if any) were likely to result from the music therapy rather than just temporal drift, providing partial control for patient fatigue and or increase familiarity with the instrument.

The STAI manual provides a standard deviation (13.24) for the State domain in male neuropsychiatric patients. This group is likely to be similar to the patient cohort proposed. A difference of about one standard deviation would be considered clinically relevant. Ten patients in total would provide adequate power $(80 \%)$ at the $5 \%$ significance level for a two tailed test to detect a 13 unit difference in the change in state domain between two sessions (Hintze, J (2004) NCSS and PASS. Number cruncher statistical systems, Kaysville, Utah. WWW.NCSS.COM) in the same patients (ie a cross-over design). One session would have music therapy in the middle the other session would have usual observation.

Each of the 10 patients who meet the eligibility criteria (eg informed consent provided etc) would be randomized (sealed envelopes allocating consecutive patients to groups by high or low random numbers (MS EXCEL) in sorted random number list) to first either having STAI followed by music therapy, followed by STAI in one week and STAI followed by usual observation, followed by STAI in a subsequent week OR STAI followed by usual observation, followed by STAI in one week and STAI followed by music therapy, followed by STAI in a subsequent week. If it is anticipated that patients may drop out or withdraw from the study between the first and second visit additional patients maybe recruited (for example it would be reasonable to aim for 12 subjects in total with the expectation that at most 2 would refuse the second measurement period).

The primary method of analysis will be by Student's paired test where the difference in State domain in the study arm with music therapy will be compared with the difference in State domain in the study arm without music therapy. $\mathrm{P}<0.05$ will be considered statistically significant.

In secondary analysis a mixed models approach to repeated measures will be used to partition variance between the study arms to test for carryover effects (ie that the baselines were different between groups depending upon when the music therapy was implemented), and to see if order changes effect size. Although these analyses will by their nature be of limited power they may serve a purpose in planning future studies.

We may in some ways consider this a pilot study since it is limited by the time and resource constraints of your requirements to complete a masters thesis nevertheless it would be possible to examine potentially large treatment effects while collecting information on the application and repeatability of the study instruments in the proposed patient group.

I hope this is of use to you Ajay.

Best wishes

Greg Gamble

Biostatistician

\author{
Greg Gamble * Department of Medicine * The University of Auckland \\ Private Bag $92019 *$ Auckland * New Zealand \\ office (+64 9) 373-7599 ×86262 * $\operatorname{tax}(+649) 373-7677^{*}$ mob 0274230959
}

http://nz.mg2.mail.yahoo.com/dc/launch?.gx=0\&.rand=ch0m4scraqo52 
Appendix F: State Part of the State Trait Anxiety Inventory

\section{SELF-EVALUATION QUESTIONNAIRE}

STAI Form $Y$-1

Please provide the following information:

Name

Date

S

Age

Gender (Circle) M F DIRECTIONS:

A number of statements which people have used to describe themselves are given below. Read each statement and then circle the appropriate number to the right of the statement to indicate how you feel right now, that is, at this moment. There are no right or wrong answers. Do not spend too much time on any one statement but give the answer which seems to describe your present feelings best.

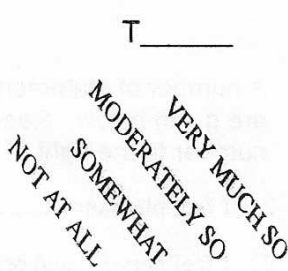
1234

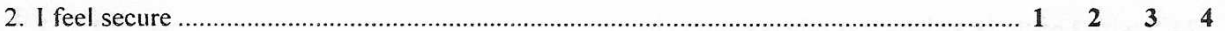

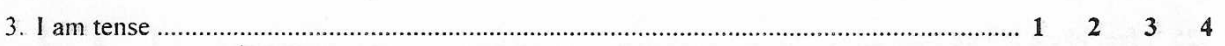

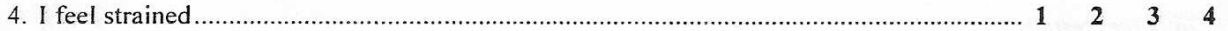

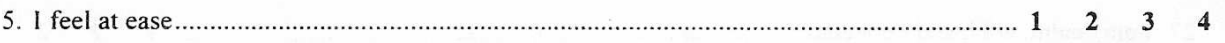

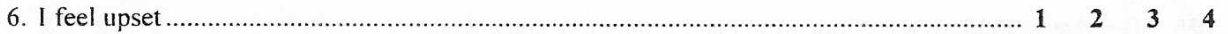

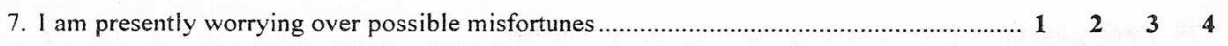

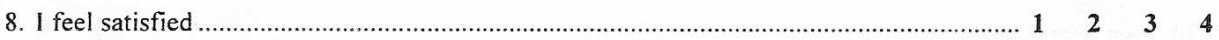

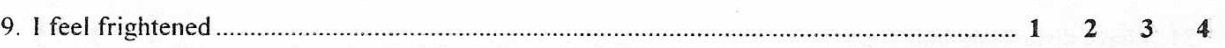

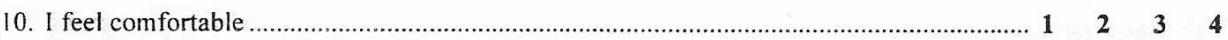

11. I feel self-confident ........................................................................................... 1

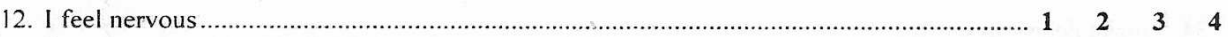

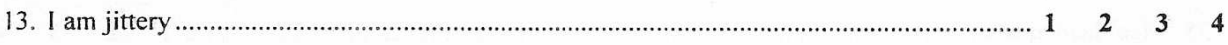

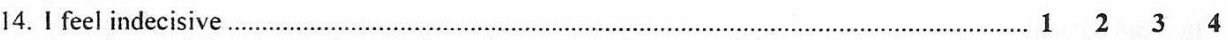

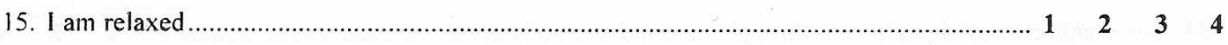

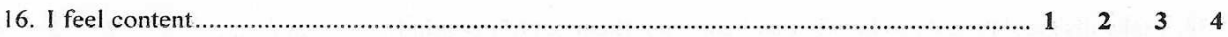

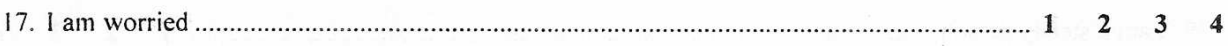

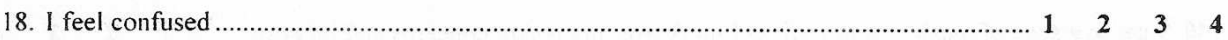

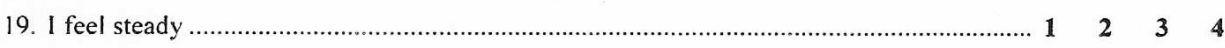

20. I feel pleasant ........................................................................................... 1 


\section{Appendix G: Project Approval from the Northern X Regional Ethics Committee, New}

Zealand

Health
and
Disability
Ethics
Committees

Email: pat_chainey@moh.govt.nz
Northerm X Regional Ethics Committee Ninistry of lealt? 3rd Foor Unisys 3 iniding 650 Great South Road, 'Bentrose frivale Bag 52522 Welleslev Street, Ausila: Pone :09 5809105 Fax (C) 580,900

24 July 2008

Mr Ajay Castelino

8 Denbigh Ave

Mt Roskill

Auckland 1041

Dear Ajay

NTX/08/06/055 The effects of singie sessions of music therapy on the level of anxiety in older persons with psychiatric disorders: PIS/Cons V\#2, 24/06/08

Principal Investigator Mr Ajay Castelino, Massey University

Supervisor: Ms Sarah Hoskyns, NZ School of Music

Thank you for your letter 9 July 2008 attaching the Committee requirements. The above study has been given ethical approval by the Northern X Regional Ethics Committee. A list of members of this committee is attached.

Approved Documents

- Information Sheet/Consent Form V\#2 dated 24 June 2008

- Self Evaluation Questionnaire V\#1 dated 24 June 2008.

- Summary Sheet V苂1 dated 24 June 2008

Certification

The Committee is satisfied that this study is not being conducted principaliy for the benefit of the manufacturer or distributor of the medicine or item in respect of which the trial is being carried out.

Accreditation

The Committee involved in the approval of this study is accredited by the Healtt? Research Council and is constituted and operates in accordance with the Operational Standard for Ethics Committees, April 2006.

\section{Final Report}

The study is approved unti! 31 December 2008. A final report is required at the end of the study. The report form is available on hittp: i/wwn.ethicscommittees.health.covt.nz (forms-progress reports) and should be forwarded along with a summary of the results. If the study will not be completed as advised, please forward a progress report and an application for extension of ethical approval one month before the above date.

\section{Requirements for SAE Reporting}

The Principal investigator will inform the Commiltee as soon as possible of the following:

- Ary sericus adverse events occurring during the study which are considered related to the study.

Ali SAE reports must be signed by the Principal Investigator and include a comment on whether he/she considers there are any ethical issues relating to this study continuing due to this adverse event. 
Amendments

All amendments (including advertisements/posters etc) to the study must be advised to the Committee prior to their implementation, except in the case where immediate implementation is required for reasons of safety. In such cases the Commitiee must be notified as soon as possible of the change.

Please quote the above ethics committee reference number in all correspondence.

It should be noted that Ethics Committee approval does not imply any resource commitment or administrative facilitation by any healthcare provider within whose facility the research is to be carried out. Where applicable, authority for this must be obtained separately from the appropriate manager within the organisation.

Yours sincerely

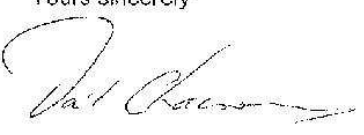

Pat Chainey

Administrator

Northern X Regional Ethics Committee

Cc: CMDHB Research Office 
Appendix H: Project approval by the Academic Committee of the New Zealand School of Music

From: Hoskyns, Sarah (S.L.Hoskyns@massey.ac.nz)

To: Ajay Castelino

Date: Wednesday, 21 May, 2008 7:33:07 PM

Cc: Claire Carruthers; Donald Maurice

Subject: Approval of Research Project by Academic Committee NZSM

Dear Ajay,

I am pleased to inform you that your research project entitled 'The effects of single sessions of music therapy on the level of anxiety in older persons with psychiatric disorders' was reviewed and approved by the Academic Committee of the New Zealand School of Music on Tuesday $13^{\text {th }}$ May.

The committee complimented you on a clear and well designed proposal.

Kind regards,

Sarah Hoskyns

Sarah Hoskyns

Associate Professor

Director of Master of Music Therapy Programme

New Zealand School of Music,

PO Box 2332

Wellington

New Zealand

T: $006448015799 \times 6410$

Email: S.L.Hoskyns@massey.ac.nz

www.nzsm.ac.nz 


\section{Appendix I: Personal Communication with Charles Spielberger re. the suitability of the State Trait Anxiety Inventory for Older Persons with Psychiatric Disorders, following the carrying out the data collection phase}

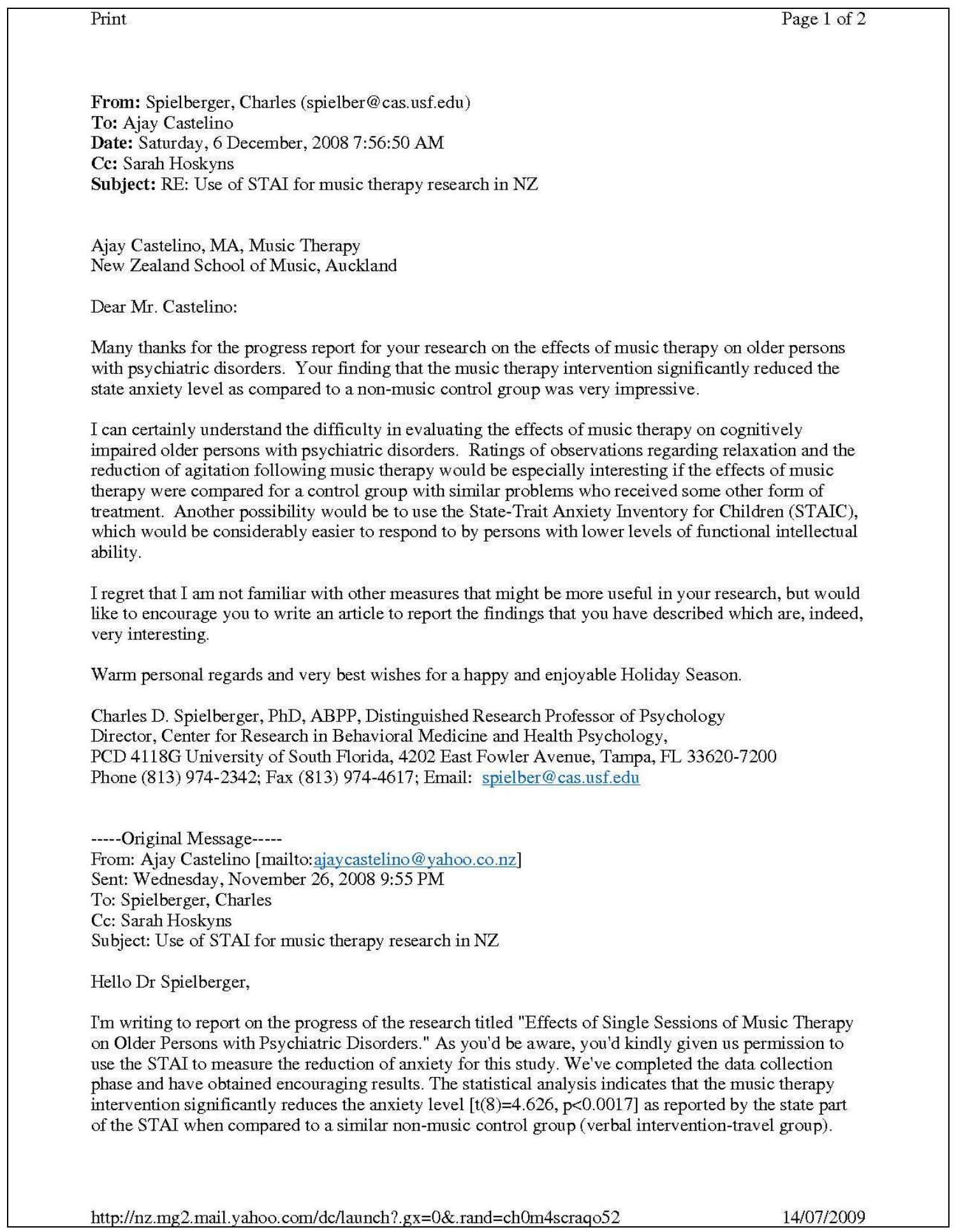

